\title{
Intraseasonal Variability of Equatorial Indian Ocean Zonal Currents
}

\author{
Debasis Sengupta \\ Centre for Atmospheric and Oceanic Sciences, Indian Institute of Science, Bangalore, India
}

ReTish SENAN

Centre for Atmospheric and Oceanic Sciences, Indian Institute of Science, Bangalore, India, and Laboratoire d'Océanographie et de Climat: Expérimentation et Approche Numérique (LOCEAN/IPSL), Paris, France

\section{B. N. Goswami}

Centre for Atmospheric and Oceanic Sciences, Indian Institute of Science, Bangalore, and Indian Institute of Tropical Meteorology, Pune, India

JÉRÔME VIALARD

Institut de Recherche pour le Developpement, and Laboratoire d'Océanographie et de Climat: Expérimentation et Approche Numérique (LOCEAN/IPSL), Paris, France

(Manuscript received 16 March 2005, in final form 14 November 2005)

\begin{abstract}
New satellite and in situ observations show large intraseasonal (10-60 day) variability of surface winds and upper-ocean current in the equatorial Indian Ocean, particularly in the east. An ocean model forced by the Quick Scatterometer (QuikSCAT) wind stress is used to study the dynamics of the intraseasonal zonal current. The model has realistic upper-ocean currents and thermocline depth variabilities on intraseasonal to interannual scales. The quality of the simulation is directly attributed to the accuracy of the wind forcing. At the equator, moderate westerly winds are punctuated by strong 10-40-day westerly wind bursts. The wind bursts force swift, intraseasonal (20-50 day) eastward equatorial jets in spring, summer, and fall. The zonal momentum balance is between local acceleration, stress, and pressure, while nonlinearity deepens and strengthens the eastward current. The westward pressure force associated with the thermocline deepening toward the east rapidly arrests eastward jets and, subsequently, generates (weak) westward flow. Thus, in accord with direct observations in the east, the spring jet is a single intraseasonal event, there are intraseasonal jets in summer, and the fall jet is long lived but strongly modulated on an intraseasonal scale. The zonal pressure force is almost always westward in the upper $120 \mathrm{~m}$, and changes sign twice a year in the 120-200-m layer. Transient eastward equatorial undercurrents in early spring and late summer are associated with semiannual Rossby waves generated at the eastern boundary following thermocline deepening by the spring and fall jets. An easterly wind stress is not necessary to generate the undercurrents. Experiments with a single westerly wind burst forcing show that apart from the intraseasonal response, the zonal pressure force and current in the east have an intrinsic 90-day time scale that arises purely from equatorial adjustment.
\end{abstract}

\section{Introduction}

The availability of new high-frequency satellite wind data and in situ observations is an important develop-

Corresponding author address: Debasis Sengupta, Centre for Atmospheric and Oceanic Sciences, Indian Institute of Science, Bangalore 560012, India.

E-mail: dsen@caos.iisc.ernet.in

DOI: $10.1175 / J C L I 4166.1$

(C) 2007 American Meteorological Society ment in the study of the equatorial Indian Ocean (EqIO) because they help to resolve the subseasonal variability (Sengupta et al. 2004; Masumoto et al. 2005). Accurate estimates of surface winds with high time and space resolutions from the Quick Scatterometer (QuikSCAT) are available from July 1999 onward (Liu 2002; Chelton et al. 2001). The first direct observations of the surface wind, upper-ocean current, and temperature in the eastern EqIO began soon after. The National Insti- 
tute of Oceanography (NIO), in Goa, India, deployed a series of moored subsurface current meters beginning in February 2000 at $0^{\circ}, 93^{\circ} \mathrm{E} ; 0^{\circ}, 83^{\circ} \mathrm{E}$; and $0^{\circ}, 77^{\circ} \mathrm{E}$ (Murty et al. 2002). The Japan Marine Science and Technology Center (JAMSTEC) deployed a moored acoustic Doppler current profiler (ADCP) in November 2000 at $400-\mathrm{m}$ depth at $0^{\circ}, 90^{\circ} \mathrm{E}$ (Masumoto et al. 2005), and a Triangle Trans-Ocean Buoy Network (TRITON) buoy in October 2001 at $1.6^{\circ} \mathrm{S}, 90^{\circ} \mathrm{E}$ (Kuroda 2002). Ongoing observations from these instruments already cover a longer period than previous in situ time series measurements in the EqIO, including those from Gan Island, Republic of Maldives (Knox 1976; McPhaden 1982), the western EqIO (Luyten and Roemmich 1982), and south of Sri Lanka (Schott et al. 1994; Reppin et al. 1999).

Here, we use an ocean general circulation model forced by 1999-2003 3-day QuikSCAT winds, validated against available data, to study the basic dynamics of intraseasonal zonal current in the upper $200 \mathrm{~m}$ of the EqIO. Although the emphasis is on intraseasonal variability, we revisit some questions related to the dynamics of the seasonal cycle.

\section{a. Seasonal jets and undercurrents}

The Gan data showed that eastward equatorial jets (Wyrtki 1973; Shenoi et al. 1999) accelerate to about 1 $\mathrm{m} \mathrm{s}^{-1}$ when a westerly wind stress abruptly increases in spring and fall, but they decelerate while the wind stress continues to be westerly; each jet is followed by a westward flow in the upper ocean lasting a month or longer. From the observed winds and currents at Gan, Knox (1976) deduced that the jets are accelerated by the zonal wind stress, but decelerated by the time-varying zonal pressure gradient (ZPG). He suggested that the westward pressure force required for momentum balance arises because the westerly wind stress temporarily raises sea level in the east relative to the west. Knox's estimate of the ZPG is broadly consistent with the difference of the sea level between the eastern and western equatorial regions of the Indian Ocean. Historical sea level data show that this difference reaches its largest value (about $0.2 \mathrm{~m}$ ) in June and December, following the eastward equatorial jets (Wyrtki 1973).

A climatology of the basin-scale ZPG in the upper $200 \mathrm{~m}$ of the EqIO has been constructed by Bubnov (1994), based on hydrographic data from 1962 to 1988 along 51 equatorial sections between $55^{\circ}$ and $90^{\circ} \mathrm{E}$. Estimates based on dynamic topography show that the ZPG in the upper $100 \mathrm{~m}$ is eastward (i.e., the pressure force is westward) throughout the year except in February and March. The seasonal cycle of the ZPG in the upper $100 \mathrm{~m}$ has practically the same phase as the equatorial zonal wind stress, with a dominant semiannual period. The ZPG in June and December (about $5 \times$ $10^{-7} \mathrm{~N} \mathrm{~kg}^{-1}$, or $\mathrm{m} \mathrm{s}^{-2}$ ) corresponds to an east-west sea level difference of about $0.2 \mathrm{~m}$. In February and March the pressure force in the upper $200 \mathrm{~m}$ is eastward, with a maximum at $100-\mathrm{m}$ depth of about $-2.0 \times 10^{-7} \mathrm{~N}$ $\mathrm{kg}^{-1}$, comparable to that in the equatorial Atlantic or Pacific.

The ZPG associated with equatorial Kelvin and Rossby waves generated/reflected at lateral boundaries determines ocean adjustment to uniform westerly wind stress. Since eastward jets are surface intensified, it has been argued that these waves must have a vertical structure resembling the second baroclinic mode (Philander and Pacanowski 1980). The semiannual subsurface zonal currents $(u)$ in the Gan and Sri Lanka data have an upward phase propagation, evidence of free waves carrying energy to deeper levels (McPhaden 1982; Reppin et al. 1999). A strong semiannual signal in the subsurface $u$ record from the western EqIO has been interpreted as vertically propagating first meridional mode Rossby waves, with a zonal wavelength of several thousand kilometers and a westward propagation speed of about $0.5 \mathrm{~m} \mathrm{~s}^{-1}$ (Luyten and Roemmich 1982). Many features of the western EqIO semiannual $u$ signal can be understood in terms of equatorial waves forced by the semiannual zonal wind stress in the presence of lateral boundaries; although the second baroclinic mode is important, several vertically standing modes are required to account for the observed vertical phase propagation (Gent et al. 1983). Le Blanc and Boulanger (2001) suggest that much of the seasonal to interannual variability of the Ocean Topography Experiment (TOPEX)/Poseidon sea surface height in the EqIO can be interpreted in terms of wind-forced Kelvin waves and first meridional mode Rossby waves, and their reflection at lateral boundaries. The speed of the Kelvin wave in the sea level data is $2 \mathrm{~m} \mathrm{~s}^{-1}$ to the east, while the long Rossby wave moves west at $0.7 \mathrm{~m} \mathrm{~s}^{-1}$. Note that the meridional structure of sea level associated with an eastward equatorial jet projects strongly onto that of a downwelling Kelvin wave. Second, since sea level changes project preferentially into first baroclinic $(n=1)$ equatorial waves, an analysis based on sea level alone is likely to underestimate the importance of the second $(n=2)$ and higher modes.

Eastward equatorial undercurrents (EUCs, defined as an eastward current in the thermocline beneath upper-ocean westward flow) in the Indian Ocean are transient features related to wave dynamics(Schott and McCreary 2001, hereafter SM). Several observations in the 
central and western EqIO show eastward EUCs in February-May, but they have been also reported during June-August (Bubnov 1994). Apart from the eastward EUC in March-May 1994 in the Sri Lanka data, there is an eastward flow at 50-150-m depth in AugustSeptember 1994, but not in 1993 (Reppin et al. 1999). The ADCP zonal current in the eastern EqIO consistently shows eastward EUCs in both seasons, that is, between December-April and June-September (Masumoto et al. 2005). Subsurface $u$ alternates between an eastward and a westward flow with a broadly semiannual period and upward phase propagation. Each distinct eastward EUC is preceded by an upward phase propagation of the semiannual eastward $u$.

Most previous studies of equatorial Indian Ocean circulation address the climatological seasonal cycle (e.g., Gent et al. 1983; McCreary et al. 1993; Anderson and Carrington 1993) or interannual variability (e.g., Reverdin et al. 1986; Saji et al. 1999; Murtugudde et al. 1999; Schiller et al. 2000). The seasonal cycle of the surface zonal current, in particular the dominant semiannual period, is determined by the phase relation between directly wind-driven flow and flow associated with waves (Han et al. 1999). In other words, the seasonal cycle of $u$ depends on the phase relation between the time-varying zonal wind stress and the time-varying zonal pressure force. The strength of the eastward jets in models is sensitive to the choice of wind stress climatology (Anderson and Carrington 1993) and the depth of the mixed layer (Han et al. 1999; Masson et al. 2004). Models forced by climatological winds consistently generate a transient eastward EUC in spring. For example, the McCreary et al. (1993) solution has an eastward EUC with a core at thermocline depth in January-March. Some models (e.g., Anderson and Carrington 1993) also have an eastward EUC in AugustSeptember. Although EUCs arise from a dynamical adjustment to westerly winds, several observational and modeling studies note that the spring EUC follows a spell of easterly winds in the EqIO (SM; Godfrey et al. 2001). It is not clear from the published literature if easterly winds are essential to generating the semiannual EUC in the Indian Ocean. Sustained easterly winds during late 1997 forced westward surface currents at the equator, equatorial upwelling, and a swift eastward EUC (Murtugudde et al. 2000). Basin-wide sea level anomalies in the tropical Indian Ocean, associated with propagating waves, persist for two seasons or more during dipole events (Webster et al. 1999). The large-scale sea level anomalies in 1993/94 or 1997/98 (Le Blanc and Boulanger 2001) imply anomalous zonal pressure gradients in the equatorial ocean (Grodsky et al. 2001). The upper-ocean pressure is essentially in phase with the wind stress on interannual as well as semiannual time scales.

\section{b. Intraseasonal variability of zonal current}

It has been known for some time that upper-ocean currents in the EqIO have substantial intraseasonal variability. For example, the weekly current data at Gan has $u$ variability at a 30-60-day period, and some evidence of submonthly variability. McPhaden (1982) suggests that the 30-60-day variability is wind forced, because it is coherent with the variability of the zonal wind stress. The 1993 fall jet in the Sri Lanka data is deep, swift, long lived, and modulated on an intraseasonal time scale (Reppin et al. 1999). The equatorial $u$ south of Sri Lanka has spectral peaks at 30-50-, 22-, and 15-day periods, whereas equatorial $v$ and off-equator $u$ have their peaks at 15 days (SM). The new direct measurements suggest that intraseasonal variability dominates the upper-ocean currents in the eastern EqIO. In the JAMSTEC ADCP data, for example, the amplitude of the 30-50-day $u$ variability at 40-m depth is $0.5 \mathrm{~m} \mathrm{~s}^{-1}$, compared to a $0.1 \mathrm{~m} \mathrm{~s}^{-1}$ semiannual signal; the dominant variability of $v$ has a 10-20-day period (Masumoto et al. 2005). The NIO subsurface current data (shallowest instrument at $100 \mathrm{~m}$ ) also show dominant 30-60-day $u$ variability, and a distinct 10-20-day oscillation of $v$ at all depths (Murty et al. 2002; Sengupta et al. 2004).

There are relatively few model studies of the dynamics of the intraseasonal variability of the Indian Ocean circulation. Moore and McCreary (1990) showed that 40-50-day variability in the western EqIO can be wind forced, whereas other studies attribute the intraseasonal variability in this region to dynamic instability of western boundary currents (SM). The work of Sengupta et al. (2001) focuses mainly on the intraseasonal variability of off-equatorial zonal currents in the region south and east of Sri Lanka, not on equatorial currents. Han et al. (2001) and Han (2005) show that the 30-60day variability of the zonal current is directly wind forced, and report a dominant 90-day peak in observed sea level in the eastern EqIO, as well as in the model upper-ocean current. The 90-day variability is attributed to a selective response ("resonance") of the ocean to weak 90-day wind variations. We have previously demonstrated the important role of the $\mathrm{ZPG}$ in the existence of intraseasonal jets in the EqIO: westerly wind bursts generate intraseasonal jets in summer, but not in winter because the stress is overcome by the westward pressure force (Senan et al. 2003). The findings of these studies are discussed later in the context of our results.

Recent work suggests that the intraseasonal variabil- 
TABLE 1. List of experiments.

\begin{tabular}{|c|c|}
\hline Name & Forcing characteristics \\
\hline Control run & 3-day running mean wind stress derived from 1999-2003 QuikSCAT winds \\
\hline Seasonal run & Seasonal wind stress, i.e., 3-day QuikSCAT winds with all sub-90-day variability removed \\
\hline NCEP run & Wind stress derived from daily mean 10-m winds from NCEP-NCAR reanalysis \\
\hline 20-day burst run & $\begin{array}{l}\text { Uniformly stratified ocean forced by a single burst of spatially uniform purely zonal wind stress; forcing } \\
\text { increases smoothly to } 0.1 \mathrm{~N} \mathrm{~m}^{-2} \text { in } 10 \text { days and drops to } 0 \text { in the next } 10 \text { days }\end{array}$ \\
\hline 60-day burst run & $\begin{array}{l}\text { Uniformly stratified ocean forced by a single burst of spatially uniform purely zonal wind stress; forcing } \\
\text { increases smoothly to } 0.04 \mathrm{~N} \mathrm{~m}^{-2} \text { in } 10 \text { days, remains constant for the next } 40 \text { days, and drops to } 0 \text { in } \\
\text { the next } 10 \text { days }\end{array}$ \\
\hline Equatorial $\tau_{x}=0$ run & Zonal wind stress within $4^{\circ}$ of the equator is prescribed to be 0 from 15 Dec to 15 Apr 2002 \\
\hline
\end{tabular}

ity of upper-ocean currents is relevant to the regional climate. For example, Loschnigg and Webster (2000) and Waliser et al. (2004) suggest that wind-forced intraseasonal currents make a significant contribution to the ocean heat transport and upper-ocean heat balance. Other studies propose that the intraseasonal variability influences the Indian Ocean temperature distribution on longer time scales (Schiller and Godfrey 2003; Waliser et al. 2004; Sengupta et al. 2004; Han 2005). On the other hand, the intraseasonal variability of the zonal winds and currents is influenced by large-scale seasonal variations of the tropical atmosphere and ocean (Chatterji and Goswami 2004; Senan et al. 2003). Observations and models suggest that the 10-60-day variability of wind, currents, and SST in the Indian Ocean (Sengupta et al. 2001; Vecchi and Harrison 2002; Saji et al. 2005, manuscript submitted to J. Climate) involves air-sea interaction (e.g., Zheng et al. 2004; Fu et al. 2003b). The role of air-sea interaction in the intraseasonal variability of the Indian Ocean climate is an active area of research (see the reviews of Webster et al. 1998; Goswami 2005; Waliser 2005).

This paper is organized as follows. Results from the QuikSCAT simulation are compared with available observations, and with a simulation forced by daily $\mathrm{Na}-$ tional Centers for Environmental Prediction-National Center for Atmospheric Research (NCEP-NCAR) reanalysis winds. We find that high quality wind forcing leads to a realistic simulation of the large-scale zonal currents in the EqIO. Experiments with idealized wind forcing aid in the dynamical interpretation of the intraseasonal variability of $u$. The model setup and the main experiments are described in the next section. In section 3 we demonstrate the ability of the model to simulate the major observed features of the equatorial circulation, and discuss the large-scale variability of the winds and currents. The dominant balance of forces that determine the evolution of the equatorial zonal flow is examined in section 4. This explicit calculation demonstrates the central importance of the rapidly varying zonal pressure force. The relevance of the ex- periments with idealized winds is also discussed in this section. Section 5 summarizes the main conclusions.

\section{The model}

We use the Modular Ocean Model version 2.2 (Pacanowski 1996) with the Indian Ocean domain $\left(30^{\circ} \mathrm{S}-\right.$ $30^{\circ} \mathrm{N}$ and $30^{\circ}-110^{\circ} \mathrm{E}$ ), having a sponge layer at $30^{\circ} \mathrm{S}$ and a wall at $110^{\circ} \mathrm{E}$. The horizontal resolution is approximately $1 / 3^{\circ}$ by $1 / 3^{\circ}$ north of $5^{\circ} \mathrm{S}$. There are 19 levels in the vertical, 6 of which are in the top $100 \mathrm{~m}$. The horizontal eddy diffusivity and viscosity are $2000 \mathrm{~m}^{2} \mathrm{~s}^{-1}$. Vertical mixing is based on the scheme of Pacanowski and Philander (1981). The topography is based on the $1 / 12^{\circ}$ data from the National Geophysical Data Center. No explicit surface fluxes of heat or freshwater are used to force the model. The surface temperature and salinity fields are relaxed to the observed annual cycle from the climatological data of Levitus (1982), with an $e$ folding time scale of 10 days.

Several model runs or experiments were performed; a list is given in Table 1. In the control run, or the QuikSCAT simulation, the model is forced by the July 1999-December 2003 3-day wind stress obtained from $0.25^{\circ} \times 0.25^{\circ}$ QuikSCAT vector wind data using a constant drag coefficient $\left(C_{d}\right)$ of $1.2 \times 10^{-3}$. This wind stress field has almost no gaps due to limited satellite swath (about $1500 \mathrm{~km}$ ) or rain. A test run with an objectively interpolated daily gridded $\left(1^{\circ} \times 1^{\circ}\right)$ wind stress field created from QuikSCAT winds (Pegion et al. 2000) gives almost identical results. The initial conditions for the control run, on 20 July 1999, came from a 15-yr simulation of the model ("NCEP" run) with the daily surface wind stress derived from the NCEPNCAR reanalysis (Kalnay et al. 1996) surface winds using the same $\mathrm{C}_{\mathrm{d}}$. The model has been forced with a low-pass version of the wind stress, obtained from the daily 1999-2002 QuikSCAT wind stress data by removing all variabilities with periods of less than 90 days. We call this the seasonal run. In addition to the control and seasonal runs, we use the results from several sensitivity 
experiments with the model ocean forced by idealized wind stress fields (Table 1); these are further described in section 4 .

\section{Variability of equatorial zonal currents}

\section{a. Comparison with observations}

Daily data from the TRITON mooring (information available online at http://www.jamstec.go.jp/jamstec/ TRITON/) show that relative to the amplitude of the seasonal cycle, the intraseasonal variability of the wind and current is stronger in the eastern EqIO than at Gan (Knox 1976). The root-mean-square (rms) difference between the weekly equivalent-neutral QuikSCAT wind speed and the in situ TRITON wind speed is about $1 \mathrm{~m} \mathrm{~s}^{-1}$. The QuikSCAT zonal wind stress is accurate, but slightly overestimates the maximum stress (Fig. 1a). The phase of the intraseasonal variability of the 10-m zonal current from the QuikSCAT simulation compares reasonably well with $10-\mathrm{m} u$ from the TRITON data (Fig. 1b), although the peak speeds can be higher in the model. The depths of the $20^{\circ}$ isotherms (d20) from the model and TRITON observations are close, but occasionally model $\mathrm{d} 20$ can be $10-15 \mathrm{~m}$ too shallow for up to a month (Fig. 1c).

The variability of the zonal pressure gradient at the equator computed from the model surface dynamic height is reasonably close to that estimated from TOPEX/Poseidon (Fu et al. 1994) and Jason-1 (Fu et al. 2003a) sea surface height data (Fig. 2). The rms difference of the 10-day model ZPG and satellite ZPG is $0.9 \times 10^{-7} \mathrm{~m} \mathrm{~s}^{-2}$, compared to the standard deviation of the daily model ZPG of $2.2 \times 10^{-7} \mathrm{~m} \mathrm{~s}^{-2}$. The time average of the September 1999-December 2003 model surface ZPG, equal to $4.26 \times 10^{-7} \mathrm{~m} \mathrm{~s}^{-2}$, has been removed from the time series in Fig. 2. If the slope were uniform, this would correspond to a sea level difference of about $0.2 \mathrm{~m}$ between $95^{\circ}$ and $60^{\circ} \mathrm{E}$. For comparison, Bubnov's estimate of the annual mean surface ZPG is $3.8 \times 10^{-7} \mathrm{~m} \mathrm{~s}^{-2}$. The anomalous dipole-related ZPG of October 1997-March 1998 represents a negative surface slope (east lower than west). Although the satellite sea levels are 10-day datasets, they do show the intraseasonal variability of the zonal slope.

The depth-time evolutions of the zonal flows at $0^{\circ}$, $90^{\circ} \mathrm{E}$ in the model and the JAMSTEC ADCP observations (Masumoto et al. 2005) agree in all major respects (Fig. 3).

1) Eastward equatorial jets extend to a depth of about $120 \mathrm{~m}$ in both the observations and the model.

2) The spring jet is a single event with a lifetime of $30-50$ days at this longitude; the fall jet is longer
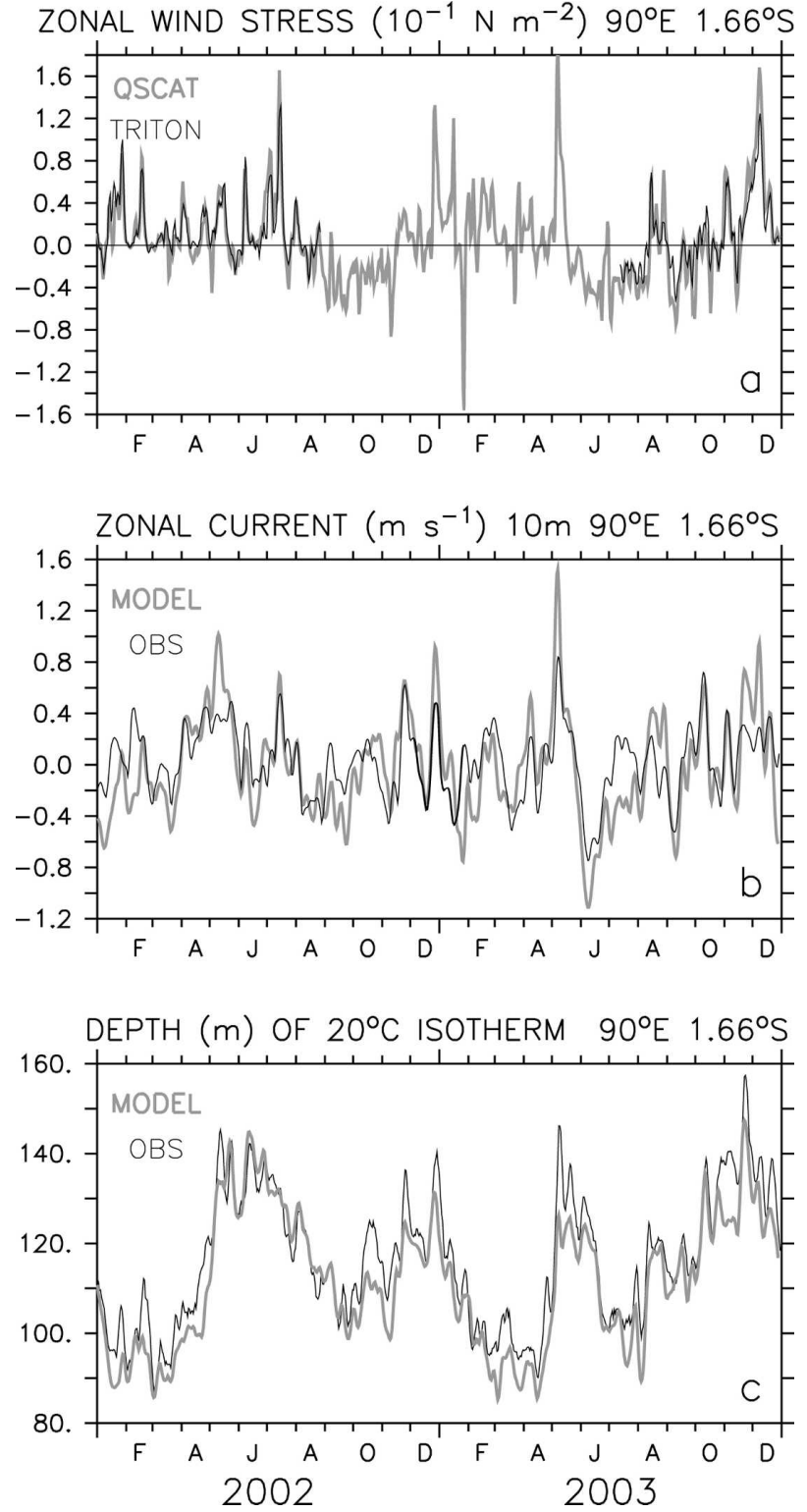

FIG. 1. Evolution of the zonal wind stress, zonal current, and $\mathrm{d} 20$ at $1.6^{\circ} \mathrm{S}, 90^{\circ} \mathrm{E}$ from TRITON data and the QuikSCAT simulation for 2002-03: (a) 3-day $\mathrm{T}_{x}\left(10^{-1} \mathrm{~N} \mathrm{~m}^{-2}\right)$, (b) 5-day $u\left(\mathrm{~m} \mathrm{~s}^{-1}\right)$ at $10 \mathrm{~m}$, and (c) 5 -day $20^{\circ} \mathrm{C}$ isotherm depth (m).

lived than the spring jet, and is modulated on intraseasonal time scales.

3) There are one or two intraseasonal eastward equatorial jets every summer. These "monsoon jets" (Senan et al. 2003) have a lifetime of about a month.

4) Subsurface zonal flow between 120 and $200 \mathrm{~m}$ is generally eastward from January to April and July to September.

5) Westward subsurface flow in October-December and May-June, and eastward subsurface flow in 


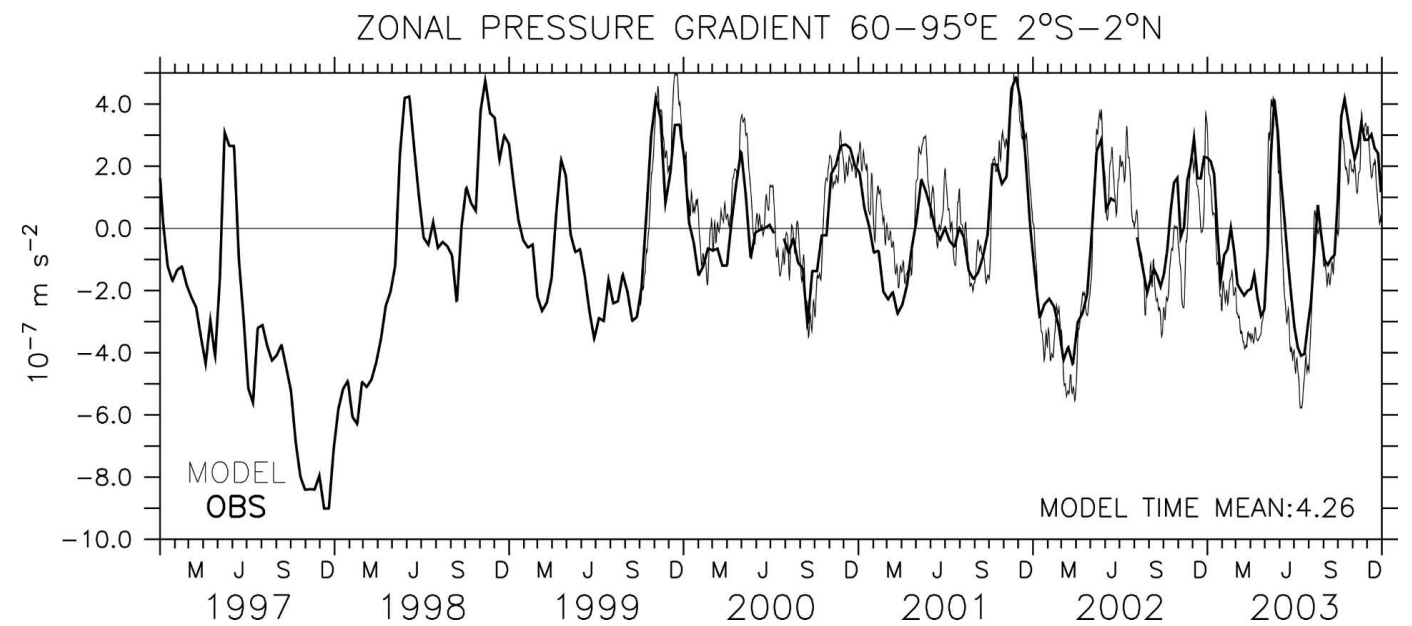

FIG. 2. The surface zonal pressure gradient averaged between $2^{\circ} \mathrm{S}-2^{\circ} \mathrm{N}$ and $60^{\circ}-95^{\circ} \mathrm{E}$ estimated from the satellite sea surface height (bold) for 1997-2003, and from the control run (thin) for July 1999-December 2003. The observations are from the TOPEX/Poseidon (January 1997-May 2002) and Jason-1 (June 2002-December 2003) altimeter readings.
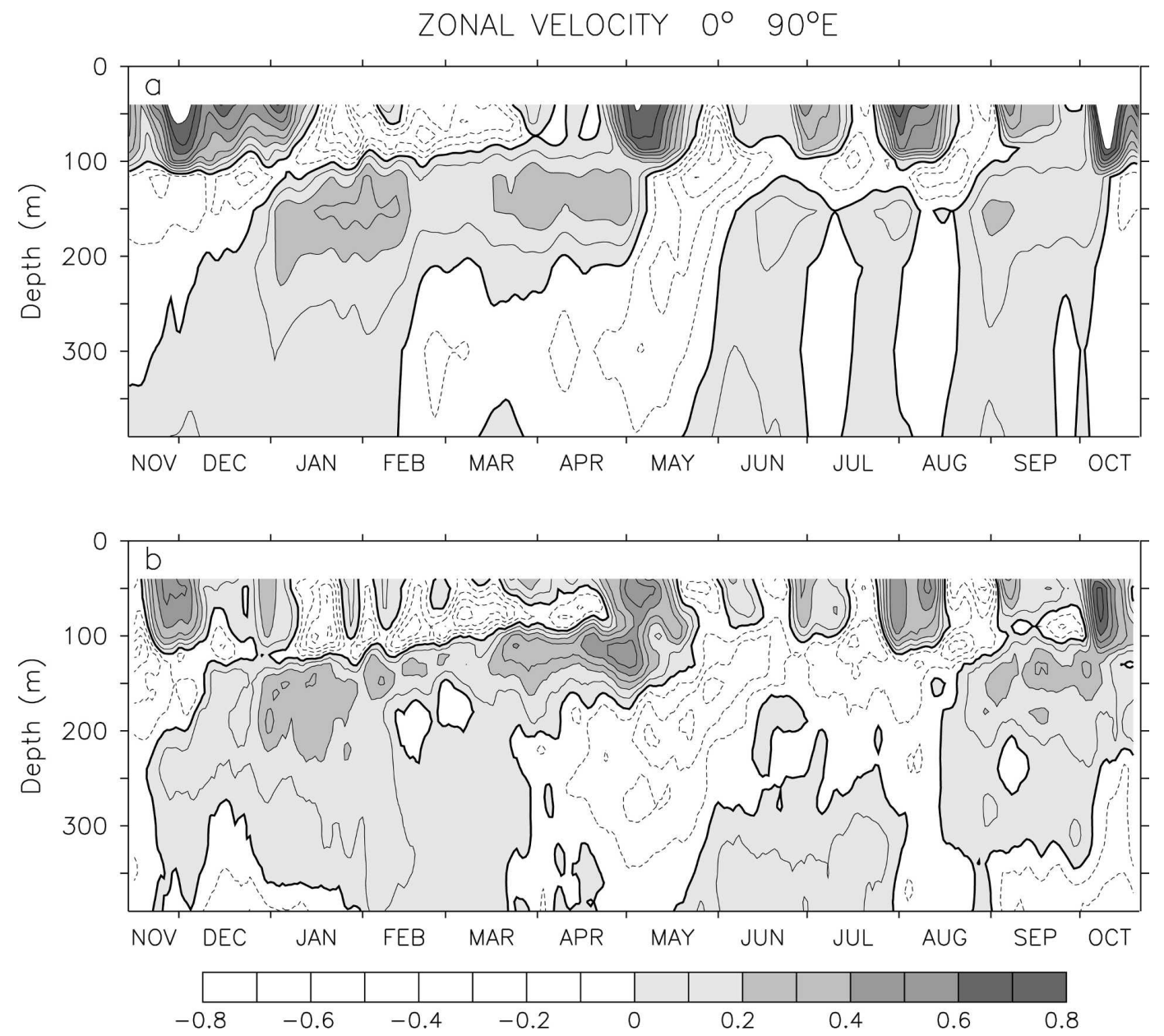

FIG. 3. Time evolution of 5-day $u\left(\mathrm{~m} \mathrm{~s}^{-1}\right)$ in the upper $400 \mathrm{~m}$ at $0^{\circ}, 90^{\circ} \mathrm{E}$ from the (a) control run and (b) JAMSTEC ADCP observations for November 2000-October 2001. (Data courtesy of Y. Masumoto.) 

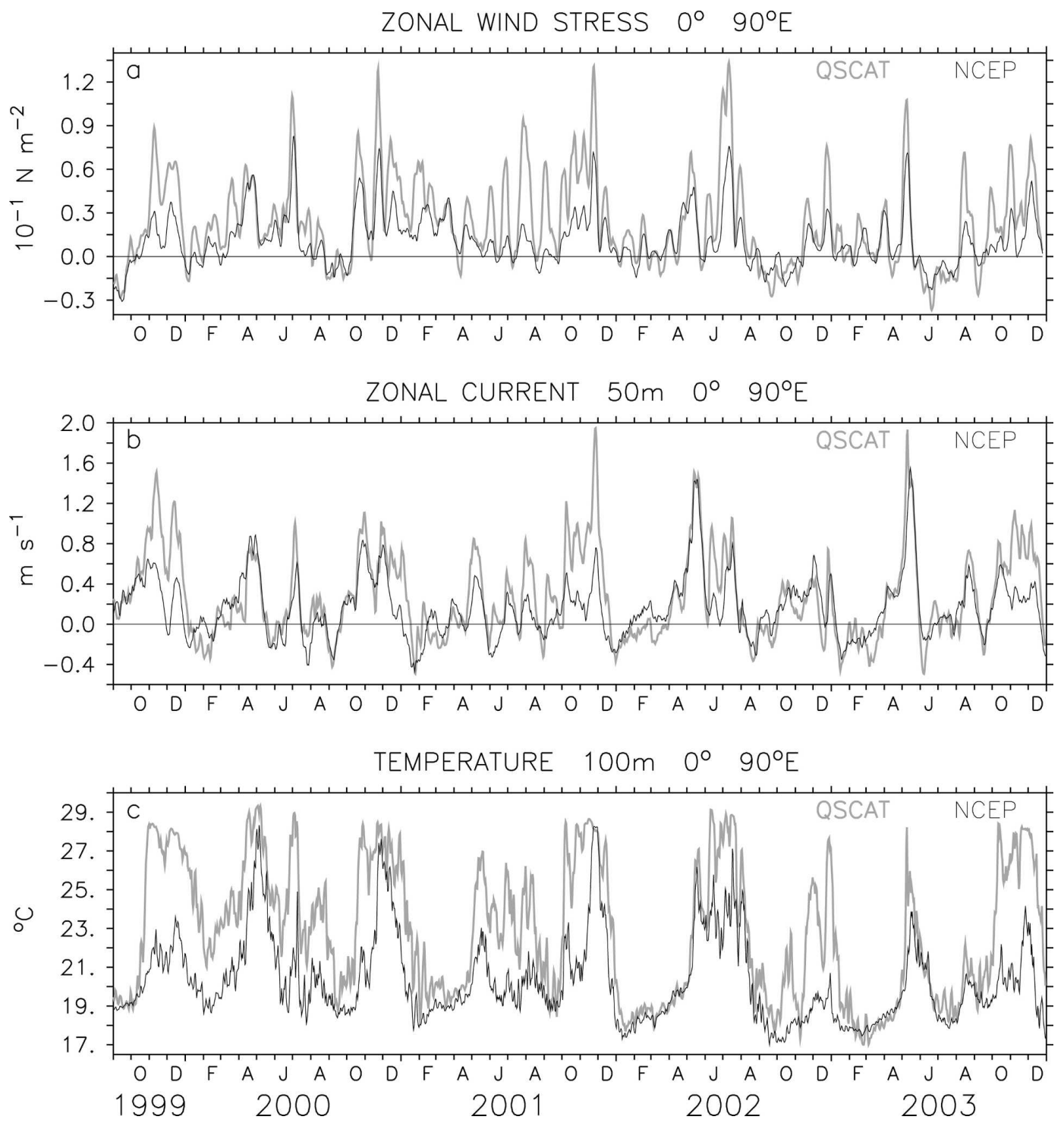

FIG. 4. Daily time series at $0^{\circ}, 90^{\circ} \mathrm{E}$ from the QuikSCAT (bold) and NCEP (thin) runs: (a) zonal wind stress $\left(10^{-1} \mathrm{~N} \mathrm{~m}^{-2}\right)$, (b) $50-\mathrm{m} u\left(\mathrm{~m} \mathrm{~s}^{-1}\right)$, and (c) potential temperature $\left({ }^{\circ} \mathrm{C}\right)$ at $100 \mathrm{~m}$.

January-February, appear first at deeper levels in the east.

The full ADCP record, November 2000-July 2003, is available (Y. Masumoto 2005, personal communication; online at http://www.jamstec.go.jp/frcgc/jp/sympo/ 2004/seika040428/ppt/10_CVORP_IO.pdf). In accord with the observations, the swiftest eastward jets in the model are in spring 2002 and 2003. The fall 2002 jet consists of three nearly distinct intraseasonal events.

The model has certain systematic shortcomings. The model fall jets are somewhat stronger, and more persistent than the observed. It is likely that the westerly wind stress is overestimated because the stress is not calculated from winds relative to the ocean surface current (M. J. Harrison 2004, personal communication). Model subsurface currents are somewhat weaker than those observed; in particular, the model eastward undercurrents at 75-150-m depth are weaker than those observed in April 2002 and March-April 2003. Comparison with temperature data from the NIO mooring at $0^{\circ}, 93^{\circ} \mathrm{E}$ suggests (Sengupta et al. 2004) that the model vertical gradient of the thermocline temperature is realistic. However, away from the equator at the location of the TRITON mooring (Fig. 1c), the model does not reproduce the nearly 100-m-deep isothermal layer in some seasons. Occasionally, the model $100-\mathrm{m}$ temperature is too cool by $2^{\circ}-3^{\circ} \mathrm{C}$, and the thermocline 
is more diffuse than that observed (not shown). These limitations might be due to the relatively coarse model vertical resolution (about $25 \mathrm{~m}$ ) below 100-m depth, as well as deficiencies in the mixing parameterization.

The equatorial Indian Ocean circulation is rather sensitive to the choice of wind product used to force the model, which is consistent with the findings of Anderson and Carrington (1993). Westerly winds in the EqIO are weak in the NCEP-NCAR reanalysis product compared to the QuikSCAT results throughout the year, particularly in the east (Fig. 4a). The seasonal mean wind speed, as well as the intraseasonal variability of the zonal wind, are underestimated in the reanalysis product. Goswami and Sengupta (2003) suggest that this is related to an inaccurate representation of the atmospheric convective heating over the eastern tropical Indian Ocean in the NCEP-NCAR model. As a consequence, the fall jet and the intraseasonal jets in the NCEP run are weak in the eastern EqIO (Fig. 4b). The correlation coefficient between TRITON and model $10-\mathrm{m} u$ is 0.73 for the QuikSCAT run and 0.60 for the NCEP run. The NCEP run 100-m temperature is systematically too cool compared to the QuikSCAT simulation (Fig. 4c); the NCEP d20 is $20 \mathrm{~m}$ too shallow relative to the QuikSCAT d20 at the equator, or to the TRITON d20 away from the equator throughout the year, except in spring (not shown). The TRITONmodel d20 correlation coefficient is 0.94 for QuikSCAT and 0.80 for NCEP. Note that surface heat and freshwater fluxes are not externally prescribed, but they come purely from a relaxation to climatology. We conclude that the model can simulate the equatorial Indian Ocean circulation with reasonable fidelity provided the surface wind forcing is accurate. This is a major result of the present study.

\section{b. Variability of wind, current, and pressure gradient}

Before taking up the dynamics of the zonal current in section 4 , we briefly describe the variability of the wind stress and zonal current fields in the north Indian Ocean, as well as the variability of the zonal pressure gradient in the equatorial region. The seasonal cycle of the QuikSCAT zonal and meridional wind stress has its largest amplitude off the African coast and in the Arabian Sea, exceeding $0.08 \mathrm{~N} \mathrm{~m}^{-2}$. The seasonal cycle of the model upper-ocean zonal current is largest in the western boundary regions off of Africa and the east coast of India. In the equatorial waveguide, the amplitude of the seasonal cycle is $0.2-0.4 \mathrm{~m} \mathrm{~s}^{-1}$ (not shown). The intraseasonal zonal wind stress $\left(\tau_{x}\right)$ variability is largest (daily standard deviation $>0.03 \mathrm{~N} \mathrm{~m}^{-2}$ ) in the
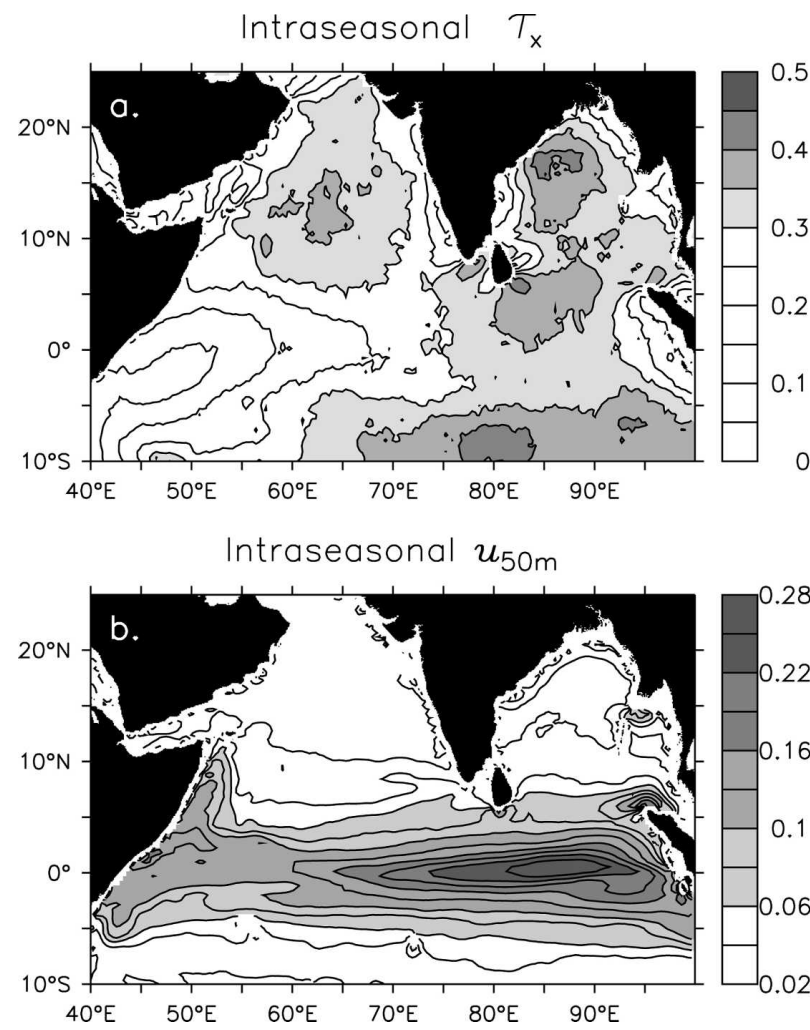

FIG. 5. Standard deviation of intraseasonal anomalies of (a) $\mathrm{T}_{x}$ $\left(10^{-1} \mathrm{~N} \mathrm{~m}^{-2}\right)$ and (b) $u\left(\mathrm{~m} \mathrm{~s}^{-1}\right)$ at $50 \mathrm{~m}$ from the control run.

central Arabian Sea and Bay of Bengal, south of Sri Lanka, and east of $75^{\circ} \mathrm{E}$ in the EqIO (Fig. 5a). Equatorial westerly wind bursts lasting 10-40 days occur throughout the year (Fig. 1; see also Fig. 5 of Knox (1976)), in response to intraseasonal variations of organized atmospheric convection (Goswami and Sengupta 2003). The intraseasonal variability of upper-ocean $u$ is largest in the equatorial waveguide. Its amplitude exceeds the seasonal variability at $90^{\circ} \mathrm{E}$, which is consistent with the finding of Masumoto et al. (2005) (see Fig. $5 b)$. There is some intraseasonal variability of $u$ in the seasonal run, with maximum amplitudes of $0.04-0.08$ $\mathrm{m} \mathrm{s}^{-1}$ in the EqIO and off of Africa (not shown), which arises from dynamic instability of the seasonal currents (Vinayachandran et al. 1996; Sengupta et al. 2001). The contribution of this instability to the intraseasonal variance of $u$ in the EqIO is generally $10 \%-20 \%$ in moderate horizontal resolution models, except west of $55^{\circ} \mathrm{E}$ where it can reach 30\%-40\% (Han et al. 2004).

Figure 6 shows 3-day and seasonal QuikSCAT $\tau_{x}$, and daily upper-ocean (0-120 m) and subsurface (120$200 \mathrm{~m}$ ) zonal currents, averaged over $60^{\circ}-95^{\circ} \mathrm{E}$, from the control and seasonal runs. The QuikSCAT zonal wind stress within a few degrees of the equator is al- 

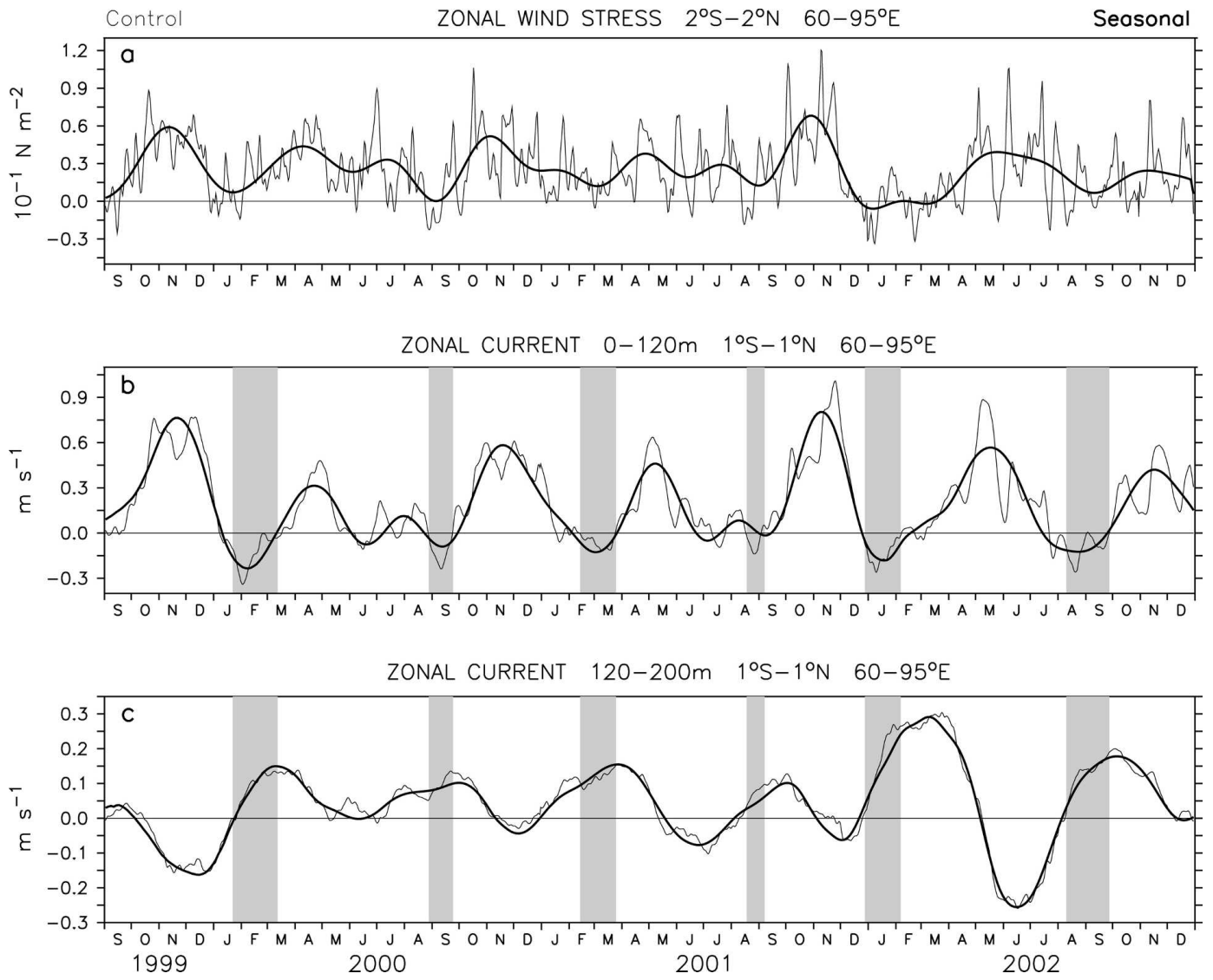

FIG. 6. Zonal surface wind stress and current from the control (thin) and seasonal (bold) runs averaged over $60^{\circ}-95^{\circ} \mathrm{E}$. (a) QuikSCAT $\tau_{x}\left(10^{-1} \mathrm{~N} \mathrm{~m}^{-2}\right)$ averaged over $2^{\circ} \mathrm{S}-2^{\circ} \mathrm{N}$, (b) upper-ocean $u\left(\mathrm{~m} \mathrm{~s}^{-1}\right)$ averaged over 0-120 $\mathrm{m}$ at $1^{\circ} \mathrm{S}-1^{\circ} \mathrm{N}$, and (c) subsurface $u\left(\mathrm{~m} \mathrm{~s}^{-1}\right)$ averaged over $120-200 \mathrm{~m}$ at $1^{\circ} \mathrm{S}-1^{\circ} \mathrm{N}$. Equatorial "undercurrents" are highlighted.

most always westerly. Episodes of westerly wind stress are generally, but not always, followed by upper-ocean eastward flow. Similarly, there is no one-to-one relation between easterly wind stress and either upper-ocean westward flow, or subsurface eastward flow. The subsurface zonal flow is generally eastward; westward flow persists for up to 3 months in October-January and May-July, with substantial year-to-year differences. Equatorial "undercurrents," with eastward flow lying underneath westward flow, occur twice every year.

The zonal extent of westerly wind bursts in the equatorial Indian Ocean is generally comparable to the basin size in spring and fall (Fig. 7a). It is smaller in summer, with strong wind bursts mainly east of $75^{\circ} \mathrm{E}$. Major westerly wind bursts $\left(\tau_{x}>0.06 \mathrm{~N} \mathrm{~m}^{-2}\right)$ rarely last more than 40 days, and occasionally propagate eastward. Eastward equatorial jets in the upper ocean are longer lived in fall than in spring (Fig. 7b), in agreement with the new time series observations (Masumoto et al. 2005) and the surface drifter climatology (Shenoi et al. 1999). Outside the fall season, strong eastward flow $\left(u>0.8 \mathrm{~m} \mathrm{~s}^{-1}\right)$ has a lifetime of less than 40 days at any longitude. Subsurface (120-200 m) $u$ is eastward much of the time (Fig. 7c). Westward flow appears first at the eastern boundary at about the same time as the strong eastward jets in the upper ocean. The envelope of westward $u$ generally propagates west at $0.5-0.8$ $\mathrm{m} \mathrm{s}^{-1}$. Many of these characteristics of the response of the equatorial current to the wind stress forcing are examined later in the paper.

The power spectra of the July 1999-December 2003 zonal wind stress, zonal current, and zonal pressure gradient from the control run show a dominant semiannual cycle and intraseasonal variability. We show the variance preserving spectra (Chatfield 1975) in order to emphasize the intraseasonal scale relative to the semiannual. Most of the intraseasonal variance is at 30-60day period (Fig. 8). All quantities used in the spectrum calculations, including the zonal pressure gradient, are from the model term balances, which represent the daily time and volume averages of the terms in the zonal momentum equation at each grid point and time 

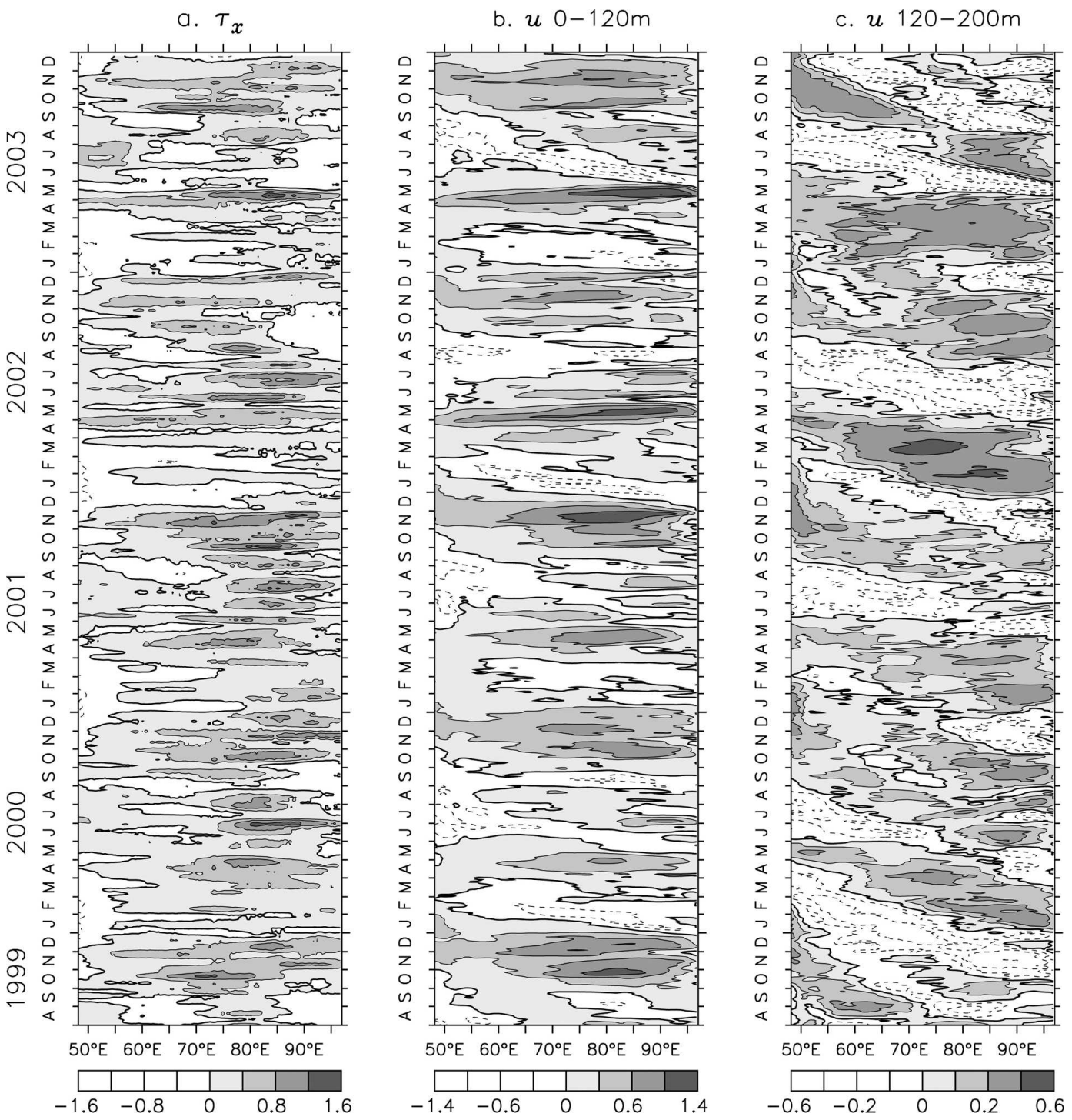

FIG. 7. Time-longitude plot of $1^{\circ} \mathrm{S}-1^{\circ} \mathrm{N}$ averaged (a) 10-day running mean QuikSCAT $\tau_{x}$

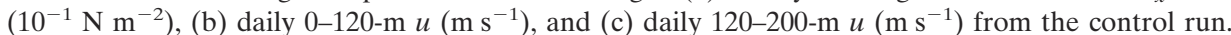

step. The semiannual variance of $\tau_{x}$ is comparable in the east and west, whereas the intraseasonal variance of $\tau_{x}$ is larger in the east (Figs. $8 \mathrm{a}$ and $8 \mathrm{~b}$ ). The variability of the zonal pressure gradient is much stronger in the east at all periods. The intraseasonal variability of $u$ is also higher in the eastern EqIO (Figs. 8c and 8d). Note that although there is a spectral valley between the intraseasonal and semiannual $\tau_{x}$, the intraseasonal variability of the upper-ocean $u$ or ZPG in the east is not clearly separated from variability with period longer than 60 days. The spectral peaks of the subsurface ZPG in the east lie at 40-60- and 80-100-day periods (Fig. 8f). We offer a dynamical explanation in the next section. Meridional currents are not discussed here. Information about the annual cycle of $\left(\tau_{y}\right)$ and $v$ can be found in Schott et al. (2002) and Godfrey et al. (2001), and discussion about the 10-20-day variability is in Sengupta et al. (2004).

\section{Dynamics of zonal currents}

\section{a. Zonal momentum balance}

We examine the zonal momentum balance in the QuikSCAT simulation in the equatorial strip at $1^{\circ} \mathrm{S}-$ $1^{\circ} \mathrm{N}, 60^{\circ}-95^{\circ} \mathrm{E}$. The western edge is chosen at $60^{\circ} \mathrm{E}$ because the dynamics of the flow might be expected to be different in the western boundary region. For simplicity, we denote the various terms in Cartesian coordinates. The model stress term is $(\partial / \partial z)[\kappa(\partial u / \partial z)]$, where $z$ is the depth and $\kappa$ the coefficient of the vertical mo- 


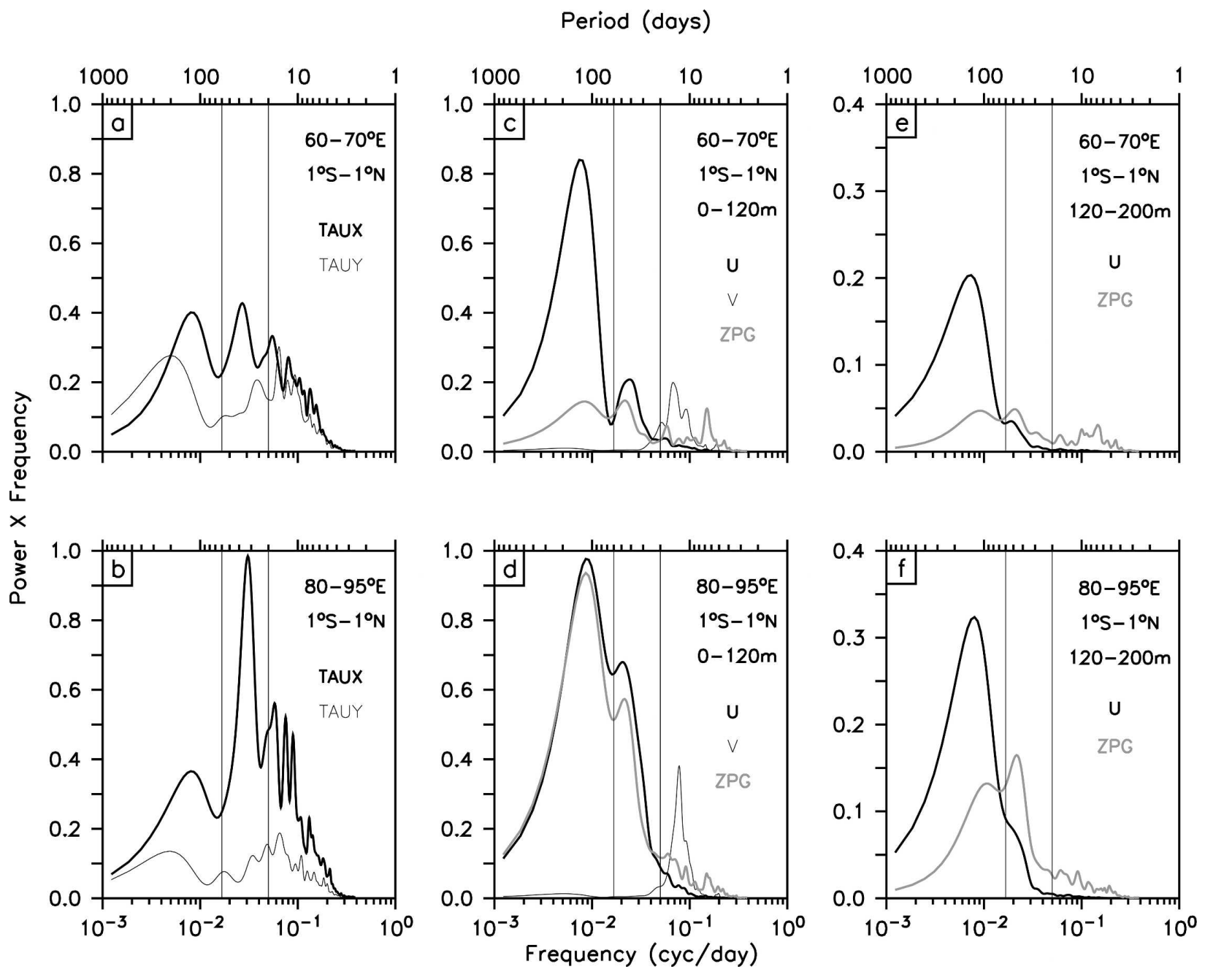

FIG. 8. Variance-preserving power spectra of July 1999-December 2003: (a) $\tau_{x}$ (bold) and $\tau_{y}$ (thin) averaged over $2^{\circ} \mathrm{S}-2^{\circ} \mathrm{N}, 60^{\circ}-70^{\circ} \mathrm{E}$; (b) as in (a) but for $80^{\circ}-95^{\circ} \mathrm{E}$; (c) control run $u$ (bold), $v$ (thin), and ZPG (gray) averaged over $0-120 \mathrm{~m}$ at $1^{\circ} \mathrm{S}-1^{\circ} \mathrm{N}, 60-70^{\circ} \mathrm{E}$; (d) as in (c) but for $80^{\circ}-95^{\circ} \mathrm{E}$; (e) control run $u$ (bold) and ZPG (gray) averaged over $120-200 \mathrm{~m}$ at $1^{\circ} \mathrm{S}-1^{\circ} \mathrm{N}, 60^{\circ}-70^{\circ} \mathrm{E}$; and (f) as in (e) but for $80^{\circ}-95^{\circ} \mathrm{E}$. Units are arbitrary, but identical for wind stress, velocity, and ZPG across (a)-(f). The lines mark the 20- and 60-day periods.

mentum mixing; integration of the stress from a sufficiently deep level to the surface gives the following model surface boundary condition:

$$
\left.\kappa(z=0) \frac{\partial u}{\partial z}\right|_{z=0}=\tau_{x} .
$$

The stress is negligible below 120-m depth, except when there is a strong equatorial jet in the upper ocean (see below). The pressure acceleration, $(-1 / \rho)(\partial p / \partial x)$, where $\rho$ is density, $p$ pressure, and $x$ the eastward coordinate, is almost always westward in the upper $120 \mathrm{~m}$. It is generally small or weakly eastward twice a year, and westward for 3-4 months following strong westerly winds in spring and fall (Fig. 9a). Like the wind stress or upper-ocean current, the zonal pressure force has a clear semiannual period, which is consistent with the climatology of Bubnov (1994). The dominant zonal momentum balance is (Fig. 9b)

$$
\frac{\partial u}{\partial t}=-\frac{1}{\rho} \frac{\partial p}{\partial x}+\frac{\partial}{\partial z}\left(\kappa \frac{\partial u}{\partial z}\right) .
$$

The zonal acceleration is generally somewhat larger than the right-hand side of Eq. (2). The vertical advection term $-w(\partial u / \partial z)$ is almost always positive, where $w$ is the vertical velocity (positive upward), and exceeds the generally negative meridional advection $v(\partial u / \partial y)$ (Fig. 9c). Our upper-ocean box is relatively deep (120 $\mathrm{m})$, but the net effect of nonlinearity is to strengthen and deepen the eastward current, in agreement with past studies (Cane 1980). The zonal advection, horizontal mixing, and Coriolis terms are generally smaller than the vertical and meridional advection terms. Zonal 

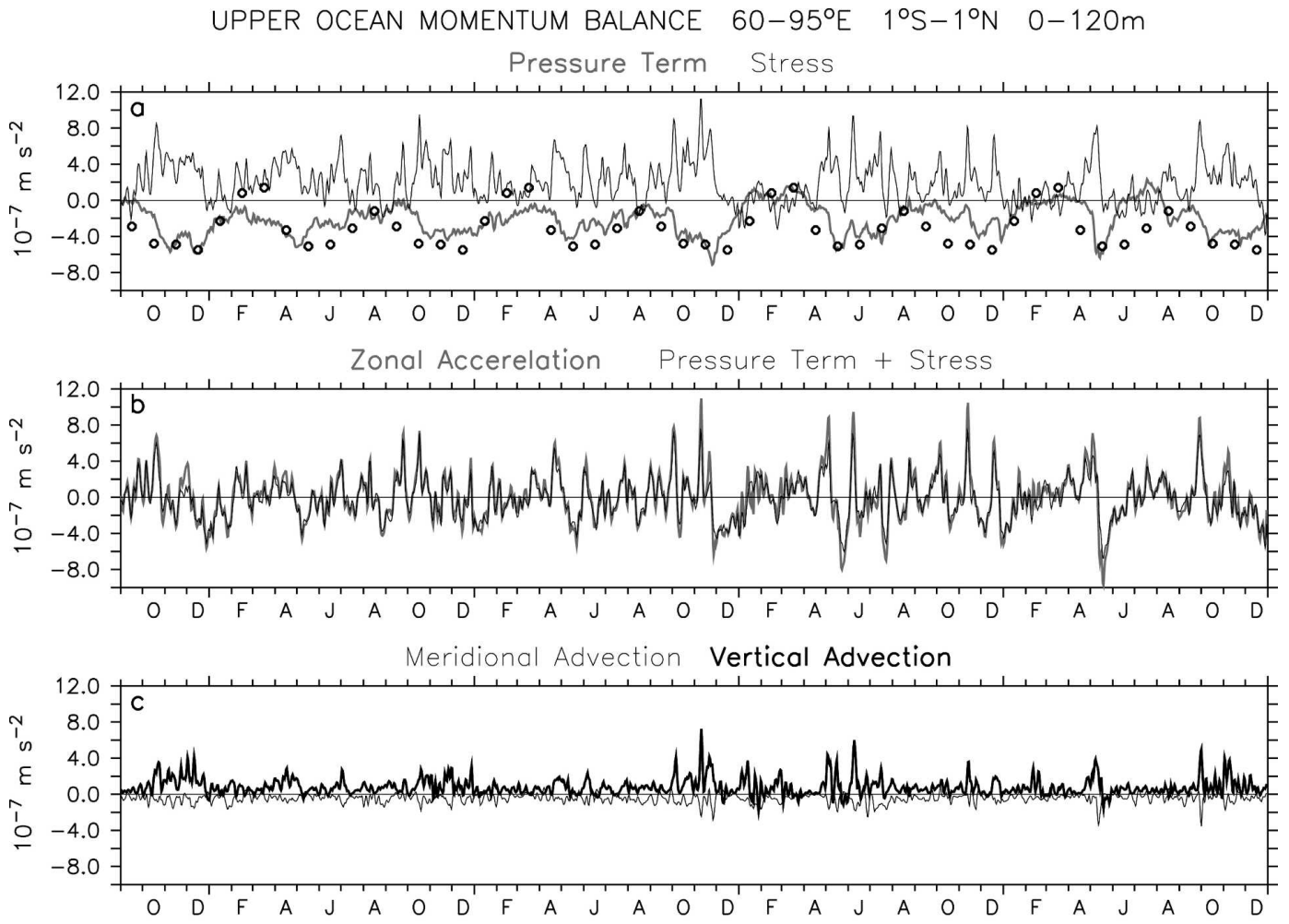

SUBSURFACE OCEAN MOMENTUM BALANCE $60-95^{\circ} \mathrm{E} \quad 1^{\circ} \mathrm{S}-1^{\circ} \mathrm{N} \quad 120-200 \mathrm{~m}$

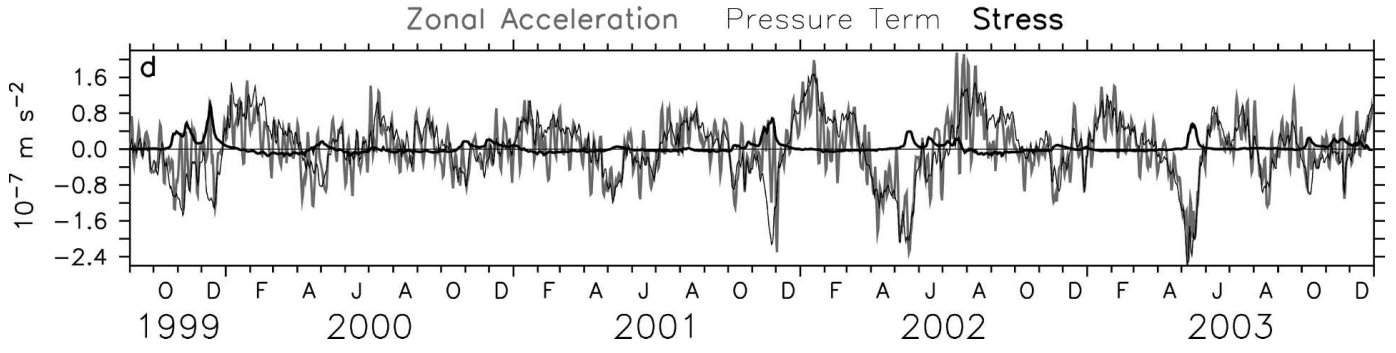

FIG. 9. Evolution of terms in the zonal momentum equation in the equatorial strip $\left(1^{\circ} \mathrm{S}-1^{\circ} \mathrm{N}, 60^{\circ}-95^{\circ} \mathrm{E}\right)$ from the control run. (a) The 0-120-m pressure term (gray) and stress (thin); the climatology of the zonal pressure gradient from Bubnov (1994) is shown by the dots. (b) The 0-120-m zonal acceleration (gray) and sum of the pressure and stress terms (thin). (c) The 0-120-m vertical (bold) and meridional (thin) advection terms. (d) The 120-200-m zonal acceleration (gray), pressure (thin), and stress (bold). Units of all terms are $10^{-7} \mathrm{~m} \mathrm{~s}^{-2}$.

advection is occasionally important; it is generally negative in the western and central EqIO but positive in the east, strengthening and prolonging eastward jets. Westerly wind bursts can lead to rapid changes in the zonal pressure force via equatorial waves. The lag correlation between the 1999-2003 daily $\tau_{x}$ in the central EqIO $\left(70^{\circ}-80^{\circ} \mathrm{E}\right)$ and the $0-120-\mathrm{m} \mathrm{ZPG}$ in the eastern EqIO $\left(80^{\circ}-95^{\circ} \mathrm{E}\right)$ has a peak of 0.6 at 15 -day lag. Therefore, pressure has considerable intraseasonal variability (Fig. 8). It can also change abruptly, as in late September 2001 and late April 2003, when it decreases by $4.0 \times$ $10^{-7} \mathrm{~m} \mathrm{~s}^{-2}$ or more in a week. Examination of the spa- tial structure of the winds suggests that such large, rapid changes of ZPG are due to Kelvin waves generated in midbasin by zonally nonuniform wind bursts.

The nature of the upper-ocean dynamical balance, and the intraseasonal variability of the terms, have important consequences. For example, the eastward jets of spring 2002 and 2003 are swift (Fig. 3), partly because the pressure force prior to these events is close to zero (Fig. 6) and does not oppose eastward acceleration. The role of pressure also helps to explain a peculiar feature in the NCEP simulation. Although the April-May westerly wind bursts are somewhat weaker in the NCEP 
results than in QuikSCAT, the speed of the spring jets are comparable in the NCEP and QuikSCAT control runs (Fig. 4). The fall jets, and the subsequent westward pressure force, are much weaker in the NCEP simulation, favoring stronger spring jets (not shown). Eastward equatorial jets are accelerated to high speed within days of onset of the westerly winds (Knox 1976; Philander and Pacanowski 1980). Our results (Figs. 7b and $9 \mathrm{~b}$ ) suggest that these jets are decelerated by the pressure gradient force (Cane 1980) within days of the weakening of the westerly wind bursts. This is the basic dynamical reason why the response of the equatorial Indian Ocean to a westerly wind burst is an intraseasonal eastward jet (Masumoto et al. 2005). However, every burst does not generate a jet. Westerly bursts in June and July generate intraseasonal eastward jets in the eastern EqIO, but westerly bursts later in summer, or in winter (albeit rare) do not, because the pressuredriven current in these periods is generally westward (Senan et al. 2003).

In the subsurface layer $\left(1^{\circ} \mathrm{S}-1^{\circ} \mathrm{N}, 60^{\circ}-95^{\circ} \mathrm{E}\right.$ and 120 $200 \mathrm{~m}$ ), the stress is generally quite small or zero, except when there is a swift equatorial jet in the upper ocean (Fig. 9d). The subsurface pressure force changes sign on semiannual time scales. It is westward following the major spring and fall jets, and eastward at other times. The zonal acceleration is small (its magnitude is less than $2.0 \times 10^{-7} \mathrm{~m} \mathrm{~s}^{-2}$ ) compared to that in the upper ocean. The dominant balance is generally $(\partial u / \partial t)=$ $(-1 / \rho)(\partial p / \partial x)$, although occasionally there is a substantial contribution from the stress. In the fall of 1999 and 2001, for instance, the vertical diffusion of eastward zonal momentum from the upper layer reaches $1.2 \times$ $10^{-7} \mathrm{~m} \mathrm{~s}^{-2}$. The vertical advection term generally accelerates eastward flow in the subsurface layer as well, although it is countered by meridional advection (Fig. 9d). The horizontal mixing and Coriolis terms are small (not shown). Based on the observed eastward time mean $u$ at all depths up to $200 \mathrm{~m}$ at Gan, McPhaden (1982) deduced that nonlinearity is important in EqIO dynamics at thermocline depths (Eriksen 1979; Philander and Pacanowski 1980; Cane 1980). The nonlinearity of the momentum balance makes it likely that intraseasonal current variability rectifies onto longer time scales (Waliser et al. 2004; Han 2005). Note that our model has restoring conditions on sea surface temperature and salinity.Therefore, it is not suitable to study rectification, which involves among other things the interaction of wind stress and mixed layer depth changes.

As most existing model studies of the Indian Ocean use monthly mean wind forcings, it is instructive to examine the dynamics of the upper-ocean zonal current in the seasonal experiment, where the wind stress has no
TABLE 2. Standard deviation of terms in the zonal momentum equation in the upper-equatorial Indian Ocean $\left(0-120 \mathrm{~m} ; 1^{\circ} \mathrm{S}-\right.$ $\left.1^{\circ} \mathrm{N}, 60^{\circ}-95^{\circ} \mathrm{E}\right)$.

\begin{tabular}{lccccc}
\hline \hline & & & \multicolumn{2}{c}{$\begin{array}{c}\text { Control } \\
\text { run }\end{array}$} & $\begin{array}{c}\text { Seasonal } \\
\text { run }\end{array}$ \\
\cline { 5 - 6 } \multicolumn{1}{c}{ Term } & Control & $\begin{array}{c}\text { Seasonal } \\
\text { run }\end{array}$ & $\begin{array}{c}\text { run } \\
\text { (normalized } \\
\text { by acceleration) }\end{array}$ \\
\hline Acceleration & 2.61 & 1.13 & 1 & 1 \\
Pressure & 1.51 & 1.40 & 0.58 & 1.24 \\
Stress & 2.22 & 1.36 & 0.85 & 1.20 \\
Vertical advection & 0.90 & 0.42 & 0.35 & 0.37 \\
Meridional advection & 0.51 & 0.21 & 0.20 & 0.19 \\
Zonal advection & 0.19 & 0.13 & 0.07 & 0.12 \\
Net advection & 0.83 & 0.28 & 0.32 & 0.25 \\
\hline
\end{tabular}

subseasonal variability. The dominant zonal momentum balance is, once again

$$
\frac{\partial u^{s}}{\partial t}=-\frac{1}{\rho^{s}} \frac{\partial p^{s}}{\partial x}+\frac{\partial}{\partial z}\left(\kappa \frac{\partial u^{s}}{\partial z}\right)
$$

where a superscript $s$ denotes variables in the seasonal run. However, the partitioning between the terms is quite different from that in the control run. The variability of the upper-ocean acceleration is much smaller in the seasonal run; the daily standard deviation of $\left(\partial u^{s} / \partial t\right)$ is 1.16 compared to 2.70 for the daily $(\partial u / \partial t)$ (Table 2). The variability of the zonal pressure force is comparable in the two runs; although the standard deviation of the stress is only $70 \%$ larger in the control run, the net nonlinearity is $200 \%$ larger. Normalized by the variability of the acceleration, however, the variability of the pressure is twice as large, the stress is 30\% larger, and the net advection 15\% larger in the seasonal run. The slowly varying currents in the seasonal run arise from the small difference between the (generally positive) stress and the (negative) pressure terms, with a substantial contribution from nonlinearity.

\section{b. Experiments with idealized winds}

The response of the EqIO to westerly wind bursts is studied with the help of two experiments (Table 1). The initial stratification of the model ocean is uniform, taken to be the annual mean Levitus temperature and salinity averaged over $10^{\circ} \mathrm{S}-25^{\circ} \mathrm{N}, 30^{\circ}-110^{\circ} \mathrm{E}$. A spatially uniform, purely zonal wind stress forces the ocean. In the 20-day burst run, it increases smoothly to $0.1 \mathrm{~N} \mathrm{~m}^{-2}$ in 10 days, and drops to 0 in the next 10 days. In the 60-day burst run, $\tau_{x}$ increases to $0.04 \mathrm{~N} \mathrm{~m}^{-2}$ in 10 days, remains constant for 40 days, and drops to 0 by day 60 . The 60-day experiment can be considered an idealization of fall, when the ocean is forced for about 2 months by westerly winds; often $\tau_{x}$ strengthens and 

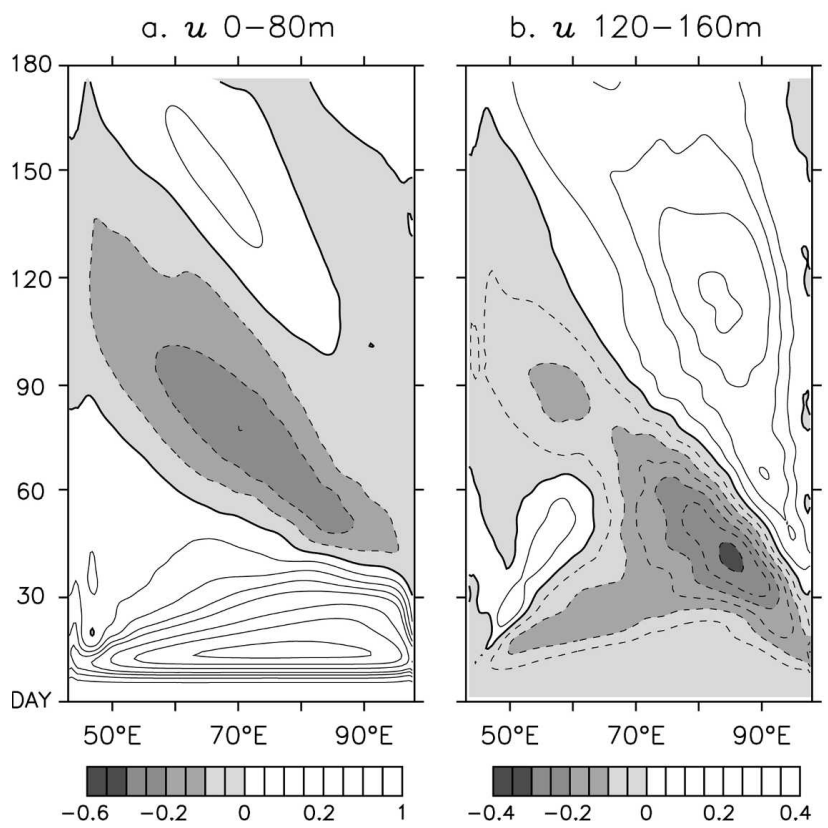

c. DYN. HT. GRAD. Om

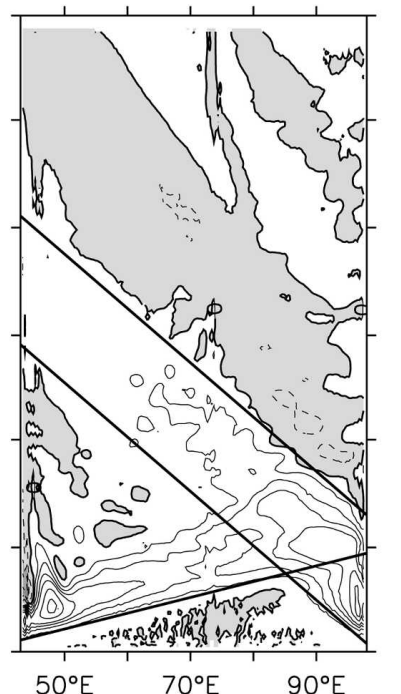

$50^{\circ} \mathrm{E}$ d. DYN. HT. GRAD. $120 \mathrm{~m}$

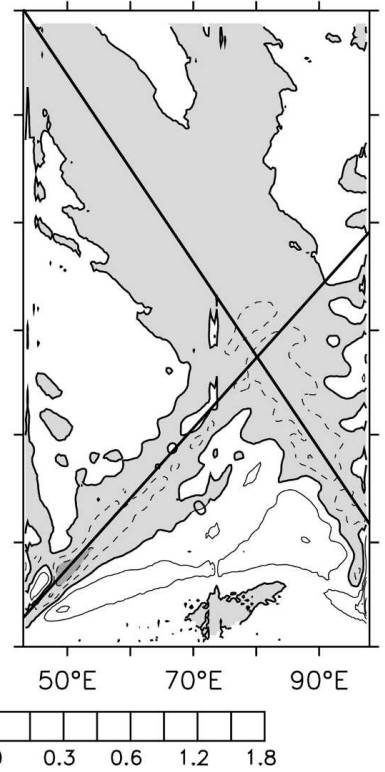

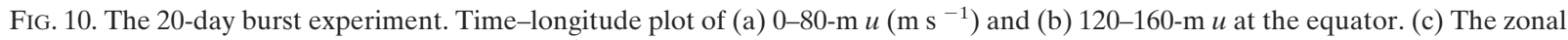
gradient of the surface dynamic height $\left(10^{-7} \mathrm{~m} \mathrm{~s}^{-2}\right)$ with respect to $500 \mathrm{~m}$. (d) Same as in (c) but for the dynamic height at $120 \mathrm{~m}$. The slopes of the lines in (c) denote the phase speeds of the fastest Kelvin $\left(2.4 \mathrm{~m} \mathrm{~s}^{-1}\right)$ and Rossby $\left(0.8 \mathrm{~m} \mathrm{~s}^{-1}\right)$ waves and in (d) are consistent with $n=2$ Kelvin and Rossby wave speeds.

relaxes abruptly $\left(0.1 \mathrm{~N} \mathrm{~m}^{-2}\right.$ change in a week). Note that upper-ocean ZPG is generally weak at the start of the fall westerly winds (Fig. 9).

The initial response of the upper ocean to the 20-day burst is an accelerating eastward equatorial jet (Fig. 10a). First and second baroclinic mode upwelling Kelvin waves and downwelling Rossby waves are generated at the boundaries to satisfy the no-volume-flux condition. The $n=1$ Kelvin wave propagates east at about $2.4 \mathrm{~m} \mathrm{~s}^{-1}$, reaching the eastern boundary on day 30; it lowers sea level, counteracting the elevation due to the wind-forced equatorial convergence. The $n=1$ Rossby wave moves west at $0.8 \mathrm{~m} \mathrm{~s}^{-1}$. The westward pressure force associated with these waves (Fig. 10c) arrests the acceleration of the eastward jet (Philander and Pacanowski 1980). (The surface dynamic height gradient selectively depicts the $\mathrm{n}=1$ mode, as discussed before.) The boundary-generated Kelvin and Rossby waves give rise to westward $u$ at almost all longitudes in the upper ocean by day 60. Upwelling Rossby waves, generated by the reflection of upwelling Kelvin waves at the eastern boundary starting at day 30 , are associated with an eastward pressure force (Fig. 10c). In the subsurface ocean, westward $u$ (Fig. 10b) is decelerated by the ZPG associated with an $n=2$ Rossby wave moving west at about $0.5 \mathrm{~m} \mathrm{~s}^{-1}$ (Fig. 10d). Comparison with term balances suggests that the upper- (subsurface) ocean ZPG estimated from the dynamic height gradient has an error of up to $10 \%(30 \%)$.

The second and higher baroclinic modes are clearer in longitude-depth sections (Fig. 11). On day 20, the eastward jet dominates the flow in the upper $100 \mathrm{~m}$ or so; the $n=1$ Kelvin wave front has arrived just west of the Chagos ridge at $73^{\circ} \mathrm{E}$, and the Rossby wave front at $83^{\circ} \mathrm{E}$ (Fig. 11a). On day 30, the $n=1$ Kelvin wave has reached the eastern boundary (see Fig. 10c), and the $n=2$ Kelvin wave is west of $65^{\circ} \mathrm{E}$ (Figs. $11 \mathrm{~b}$ and 10d). Forty days later, the $n=1$ and $n=2$ direct Rossby waves are west of $73^{\circ} \mathrm{E}$; the reflected upwelling Rossby waves, which have higher amplitude than the direct Rossby wave, are associated with the eastward subsurface $u$ in the eastern basin (Fig. 11c). Snapshots of the horizontal currents show the propagation of the reflected Rossby wave, and suggest that it has a vertical structure resembling a second baroclinic mode (Figs. 11e and 11f), with zero crossing in the upper ocean. The direct Rossby wave is also discernible at subthermocline depth, to the west of the reflected wave (Fig. 11f). Eventually, $n=2$ and higher baroclinic mode Rossby waves give rise to increasingly surfaceintensified eastward $u$ (Fig. 11d) that effectively moves slowly westward at about $0.3-0.4 \mathrm{~m} \mathrm{~s}^{-1}$, as seen in Figs. 

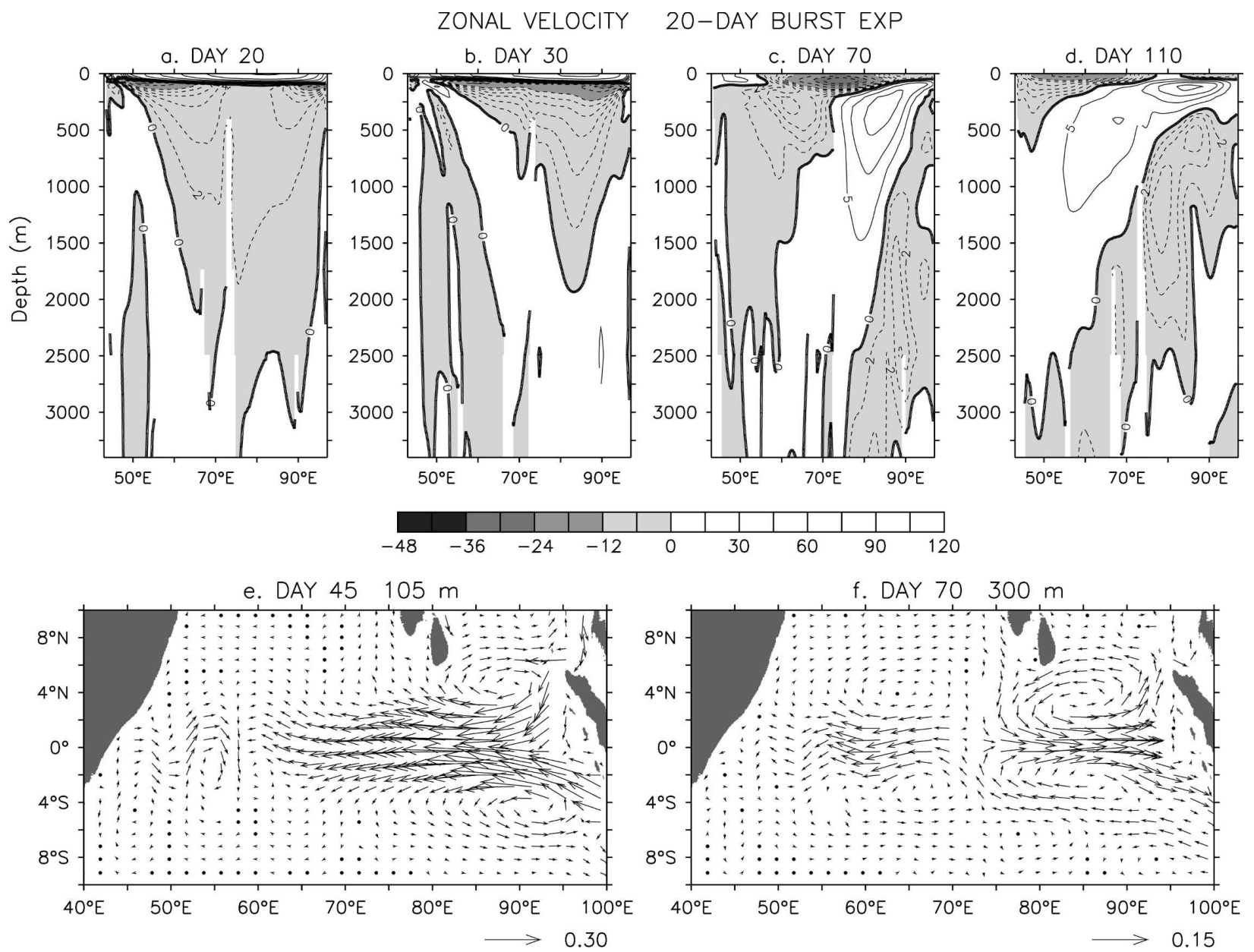

FIG. 11. Depth-longitude structure of $u\left(\mathrm{~m} \mathrm{~s}^{-1}\right)$ at the equator from the 20-day burst experiment on days (a) 20, (b) 30, (c) 70, and (d) 110. Snapshots of horizontal currents on (e) day 45 at $105 \mathrm{~m}$ and (f) day 70 at $300 \mathrm{~m}$.

10a and 10d. There is evidence of higher baroclinic mode Kelvin waves near the western boundary. However, these are attenuated by the midbasin (Figs. 11b, $10 \mathrm{c}$, and 10d). Generation of the $n=2$ Kelvin wave does not appear to be sustained for long, possibly due to upwelling, which rapidly reduces the directly windforced eastward volume flux near the western boundary.

The evolution of the equatorial $u$ in the 60-day burst experiment is qualitatively similar. It takes about a month longer to replace the eastward jet by the westward flow in the 60-day run (Fig. 12) than it does in the 20-day run (not shown). The momentum balance suggests that upper-ocean westward $u$ cannot appear until the westerly wind stress is switched off (Philander and Pacanowski 1980). The upper-ocean zonal pressure force is westward in the first 80 or 90 days in both the 60- (Fig. 12a) and 20-day runs; subsequently, it is weakly eastward. As in the control run, the upper- ocean zonal acceleration is mainly due to stress and pressure; nonlinearity strengthens the jet and prolongs the eastward flow by several days (Philander and Pacanowski 1980) (Figs. 12b and 12c). The pressure force in the subsurface ocean has the same sign as in the upper layer until days 50 or 60 , after which it is eastward for just over 2 months (Fig. 12d). The adjustment of the upper $200 \mathrm{~m}$ of the ocean to a single westerly burst is essentially complete [i.e., $(\partial u / \partial t)$ becomes small] in 6-7 months in both experiments.

Once a zonal pressure gradient is set up by a westerly wind burst, its relaxation time can be longer than the burst duration. An important finding is that the variability of the ZPG in the upper $200 \mathrm{~m}$ has an intrinsic 80-100-day time scale. The burst experiments suggest that the pressure time scale is independent of the forcing duration. We propose that this internal time scale explains the absence of a spectral valley between the intraseasonal and semiannual variabilities of the ZPG 
MOMENTUM BALANCE $70-80^{\circ} \mathrm{E} 1^{\circ} \mathrm{S}-1^{\circ} \mathrm{N} \quad 60-$ DAY BURST EXP
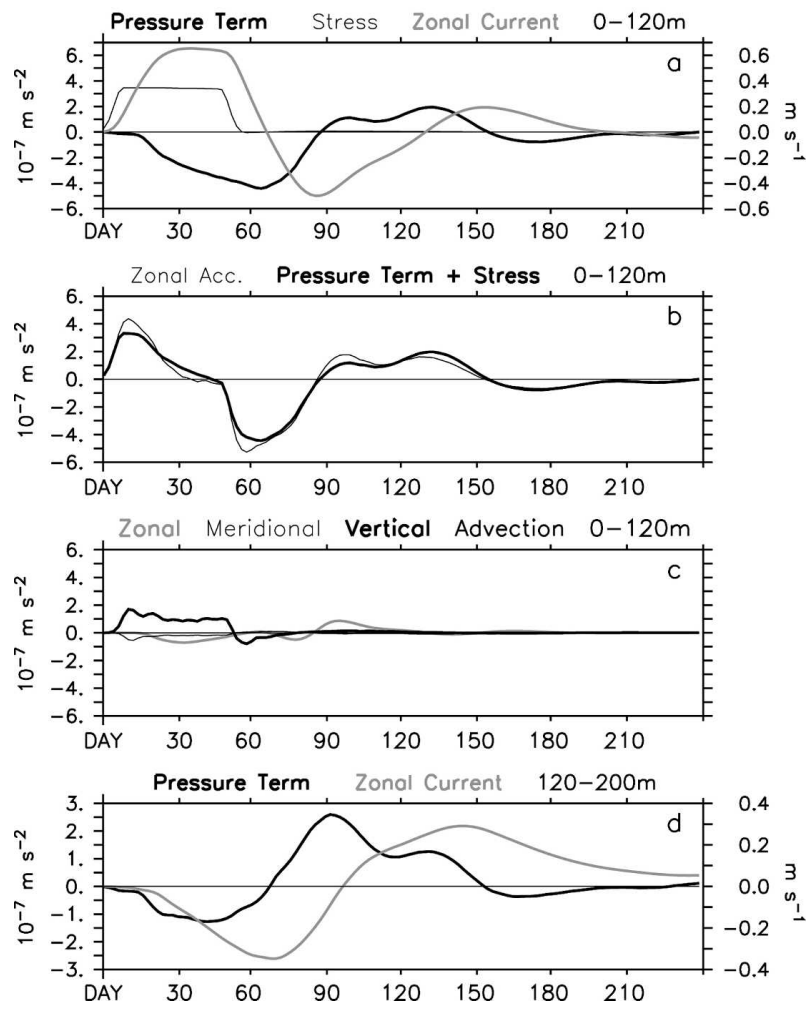

FIG. 12. Evolution of terms in the momentum equation in the central Indian Ocean $\left(1^{\circ} \mathrm{S}-1^{\circ} \mathrm{N}, 70^{\circ}-80^{\circ} \mathrm{E}\right)$ from the 60-day burst experiment: (a) 0-120-m $u$ (gray), pressure term (bold), and stress (thin); (b) 0-120-m zonal acceleration (thin) and sum of pressure and stress terms (bold); (c) 0-120-m zonal (gray), meridional (thin), and vertical (bold) advection terms; and (d) 120-200-m pressure term (bold) and $u$ (gray). Units of all terms are $10^{-7}$ $\mathrm{m} \mathrm{s}^{-2} ; u$ is in $\mathrm{m} \mathrm{s}^{-1}$.

and $u$ in the eastern EqIO (Fig. 8). Our finding is consistent with the presence of a statistically significant 90-day peak in observed sea level in the eastern EqIO (Qiu et al. 1999; Han et al. 2001). Previous studies using ocean models forced by NCEP reanalysis winds show that the 90-day variability in sea level and zonal current is associated with equatorial waves (Han et al. 2001; Han 2005). The NCEP zonal wind stress has a 90-day spectral peak, leading to the suggestion that the strong 90-day ocean response in the model is mainly due to resonant excitation of $n=2$ waves, as well as to directly wind-forced variability. [The possibility of resonance on a semiannual scale was proposed by Jensen (1993) and others (SM).] However, the QuikSCAT zonal wind stress does not have a 90-day peak. Therefore, it is not likely that the 90-day time scale of the ocean variability is due to the 90-day wind forcing. The 90-day scale is intrinsic to the equatorial Indian Ocean adjustment to westerly $\tau_{x}$. Second, the burst experiments suggest that upward phase propagation in the subsurface ocean (not shown) is associated with baroclinic Rossby waves generated at the eastern boundary; boundary waves are also responsible for the qualitatively different evolution of the pressure force in the upper and subsurface ocean (see Fig. 9).

The burst runs show that an easterly wind is not necessary for the generation of transient upper-ocean westward flow or eastward undercurrents, which is in agreement with previous work (SM; Cane 1980). Eastward subsurface $u$, appearing in the eastern EqIO weeks after the end of a westerly wind burst, can subsequently lie beneath westward $u$ (Figs. 11 and 12). An EUC is therefore expected twice a year (Bubnov 1994; Reppin et al. 1999), following the sustained westerly winds in October-December and April-May. An estimate of the contribution of the easterly $\tau_{x}$ winds to EUC transport comes from the "equatorial $\tau_{x}=0$ experiment" (Table 1). A zonal wind stress is prescribed to be zero within $4^{\circ}$ of the equator from 15 December 2001 to 15 April 2002 (Fig. 13a); there are two episodes of significant easterly $\tau_{x}$ in this period (see Fig. 6). The 15 February-15 April 2002 EUC transport between $2^{\circ} \mathrm{S}-2^{\circ} \mathrm{N}$ and $60-200-\mathrm{m}$ depth, averaged over $60^{\circ}-90^{\circ} \mathrm{E}$, is about 15.5 Sverdrups $\left(\mathrm{Sv} \equiv 10^{6} \mathrm{~m}^{3} \mathrm{~s}^{-1}\right)$ in the control run and $12 \mathrm{~Sv}$ in the experiment (Fig. 13b); the EUC speed is $20 \%-30 \%$ higher in the control run (Figs. 13c and 13d). Although the easterly winds are not essential to generating the EUC in the Indian Ocean, they can enhance the subsurface eastward transport.

The relatively short time scale of adjustment for the equatorial Indian Ocean is associated with basin size. Giese and Harrison (1990) forced a model of the Pacific with a stationary 20-day westerly wind burst with zonal and meridional extents of $20^{\circ}$ and $6^{\circ}$, respectively. A succession of free first, second, and higher mode baroclinic Kelvin waves generated by the westerly wind burst is seen east of the forcing region. Due to the large zonal extent of the Pacific basin, $n=1,2$, and 3 Kelvin wave packets are well separated in longitude by day 60 . These waves reflect as Rossby waves at the eastern boundary; however, the Rossby waves give weak westward $u$ even with a $2.0 \mathrm{~N} \mathrm{~m}^{-2}$ wind burst, except near the eastern boundary. The Rossby waves in our 20-day burst experiment carry a much larger $u$ signal to the central and western Indian Ocean because of the small basin size and the larger fetch of our zonally uniform wind burst. We note that free Kelvin waves forced in midbasin by westerly bursts are apparent in the Indian Ocean as well. For example, the intraseasonal eastward-propagating $u$ signals in August-November 2002 (Figs. 6, 7b, and 7c) appear to be associated with $n=1$ 


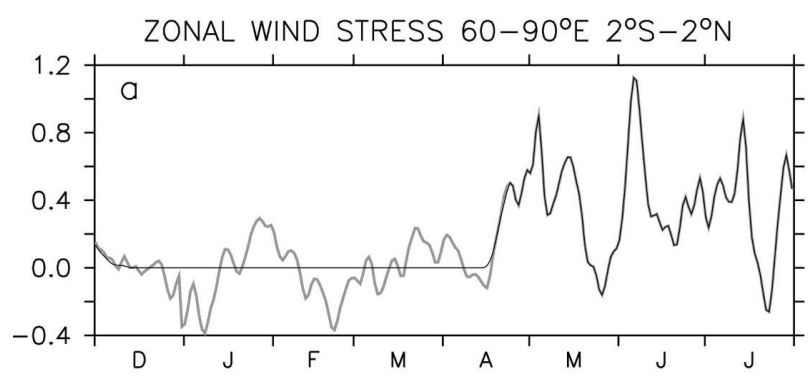

ZONAL TRANSPORT $60-90^{\circ} \mathrm{E} 2^{\circ} \mathrm{S}-2^{\circ} \mathrm{N} 60-200 \mathrm{~m}$

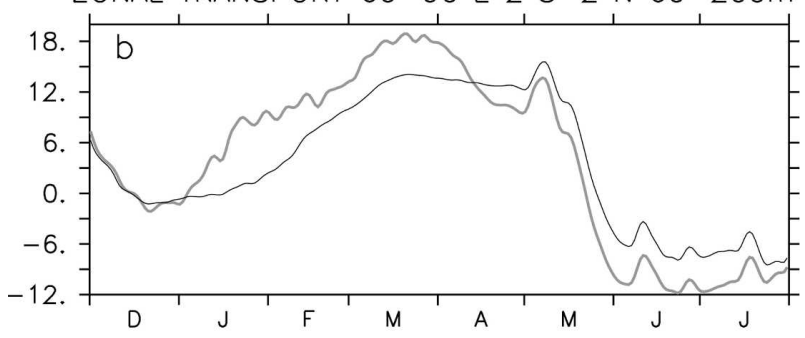

ZONAL VELOCITY $60-90^{\circ} \mathrm{E} 15$ Feb-15 Apr 2002 c. Control

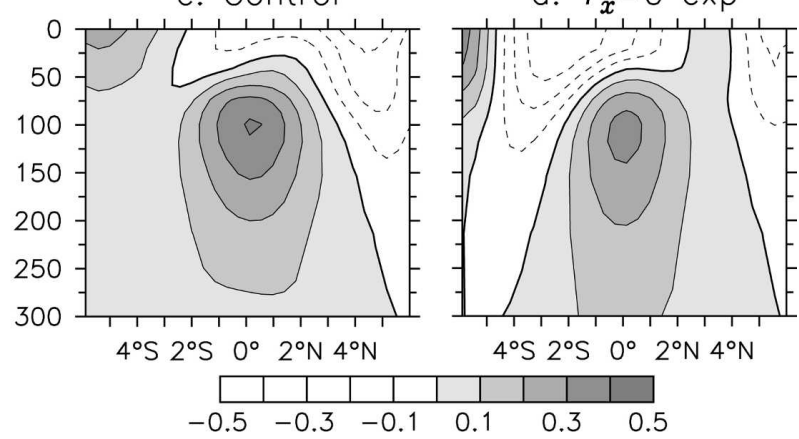

FIG. 13. Zonal wind stress and zonal flow in the control run (gray) and the equatorial $\tau_{x}=0$ experiment (black): (a) $2^{\circ} \mathrm{S}-2^{\circ} \mathrm{N}$, $60^{\circ}-90^{\circ} \mathrm{E}$ average $\tau_{x}\left(10^{-1} \mathrm{~N} \mathrm{~m}^{-2}\right)$ for December 2001-July 2002, (b) $2^{\circ} \mathrm{S}-2^{\circ} \mathrm{N}, 60^{\circ}-90^{\circ} \mathrm{E}$ averaged zonal transport (Sv) in the 60 200 - $\mathrm{m}$ depth range, (c) depth-latitude section of $60^{\circ}-90^{\circ} \mathrm{E}$ average $u\left(\mathrm{~m} \mathrm{~s}^{-1}\right)$, and (d) as in (c) but for the equatorial $\tau_{x}=0$ experiment.

and $n=2$ free downwelling Kelvin waves forced by zonally nonuniform $\tau_{x}$ (Fig. 7c).

\section{Conclusions}

Accurate, high-frequency QuikSCAT surface wind stress data are used to force an Indian Ocean general circulation model. Comparison with satellite sea level and new in situ observations from the eastern EqIO shows that the model simulation of equatorial upperocean currents, thermocline depth, and zonal pressure gradient is fairly accurate on intraseasonal to interannual scales. When the model is forced by daily NCEP winds, the intraseasonal variabilities of the model cur- rents and subsurface temperature have large differences with observations. The realism of the QuikSCAT simulation is due to the quality of the satellite wind product. Most of the intraseasonal variability in the equatorial waveguide is directly forced by the variability of the wind. A part of the intraseasonal variability near the western boundary and in the eastern Indian Ocean arises from dynamic instability of the seasonal flows. The QuikSCAT simulation captures the observed intraseasonal variability in spite of the presence of instability. An important implication is that equatorial Indian Ocean circulation in the open ocean is a deterministic response to wind forcing. Away from western boundaries, instabilities cannot grow to large amplitude because their energy is rapidly removed by propagating waves (Philander 1990; Sengupta et al. 2001).

Climatologies suggest that zonal wind speed increases with distance from the Indian Ocean equator; the line of zero zonal wind lies close to the equator at most longitudes, particularly in summer and winter (Saji and Goswami 1996). The NCEP reanalysis winds are reasonably accurate in the Bay of Bengal or Arabian Sea, but the intraseasonal variability of the zonal wind has a weak bias in the EqIO. Westerly wind bursts, associated with atmospheric convection in the central and eastern EqIO, are weak in the reanalysis product (Goswami and Sengupta 2003). The highresolution QuikSCAT zonal wind consists of a series of intraseasonal westerly wind bursts, which are most intense in the central and eastern EqIO. Between July 1999 and December 2003, strong westerly bursts are absent only in the winters of 2001-2002 and 2002-2003, and in June-July 2003 (Fig. 6). The zonal scale of the wind bursts is comparable to the size of the basin except in summer, when they occur in the east. The zonal wind stress has a distinct variability on semiannual and intraseasonal (10-30 and 30-60 days) time scales. The zonal upper-ocean current at the equator also has two distinct, directly wind forced, spectral peaks at semiannual and 30-60-day periods. The spring Wyrtki jet consists of a single intraseasonal event with a lifetime of $30-50$ days at $90^{\circ} \mathrm{E}$. The fall Wyrtki jet is longer lived, but is modulated on intraseasonal time scales, or actually consists of two or more intraseasonal jets. There are one or two intraseasonal eastward jets each summer in the eastern EqIO (the monsoon jets), but not in winter. The subsurface $u$ is mainly semiannual (Gent et al. 1983; Masumoto et al. 2005), with some intraseasonal variability forced by the zonal pressure force.

Eastward equatorial jets accelerate within days of the onset of westerly winds. If the jets have a lifetime of 20-50 days, as the direct observations show, they must 
be rapidly decelerated. Experiments with 20- and 60day zonally uniform westerly wind burst forcings suggest that the westward pressure force associated with Kelvin and Rossby boundary waves decelerates eastward jets within days of the weakening of a burst. The simulation suggests that large, abrupt pressure changes are due to Kelvin waves generated in midbasin by zonally nonuniform wind bursts. Westerly bursts in the central EqIO create a westward pressure force in the east in about 15 days. The relatively small basin size ensures that the westward pressure force propagates rapidly to the central EqIO. Apart from the semiannual and intraseasonal peaks, the upper-ocean zonal pressure gradient and currents have an 80-100-day variability (Fig. 8), which is absent from the QuikSCAT zonal wind. The wind burst experiments confirm that the 90day response is independent of the time scale of the forcing. It arises from the natural time scale of the evolution of the zonal pressure force associated with boundary waves. In other words, the 90-day time scale is intrinsic to the equatorial adjustment of the Indian Ocean to intraseasonal westerly winds.

In all generality, the evolution of the equatorial circulation is a nonlinear problem because the pressure force depends on the zonal flow. However, the strongest nonlinearity in the upper-ocean zonal momentum balance comes from the vertical advection term $w(\partial u / \partial z)$ (Fig. 9; Table 2). Fluctuations of the vertical velocity $w$ and vertical shear of $u$ are both more responsive to fluctuating stress than to the zonal pressure force. Although nonlinearity is a significant component of the dynamical balance, it does not dominate the evolution of $u$ (Fig. 9b) (Sengupta et al. 2001). There is an eastward equatorial undercurrent in July-September each year, in addition to the spring undercurrent. Neither the westward current in the upper ocean nor the subsequent eastward flow (the observed early spring and late summer EUC) requires easterly winds; they are mainly generated by variable westerly winds via wavemediated equatorial adjustment. For example, the contribution of the December 2001-March 2002 easterly winds to the transport of the February-April 2002 eastward undercurrent is only $20 \%$. In general, the response to wind bursts is determined by the wind stress and zonal pressure force, with a substantial contribution from nonlinearity. The quantitative dynamical balance is rather different in an experiment where the model is forced by smoothed seasonally varying winds with no wind bursts. The current in the seasonal run evolves slowly in response mainly to the difference between the seasonal stress and the seasonal pressure force, which have comparable magnitudes (Table 2) but differ in phase. The satellite and in situ observations show that continual intraseasonal changes in stress and pressure do not permit the upper-equatorial Indian Ocean such a slow approach toward equilibrium. Our analysis of zonal currents in the upper $200 \mathrm{~m}$ of the ocean, based on new wind observations, focuses on the simplest features of the dynamics of the intraseasonal and seasonal variabilities. We have not examined the interannual variability because the QuikSCAT wind record is not long, nor have we addressed more involved questions such as the possibility of rectification, or of resonance. The present results might provide a basis for further investigation of these and related questions.

Acknowledgments. We acknowledge the Department of Ocean Development for continued support. Discussions with V. S. N. Murty and Y. Masumoto about the observations, and D. S. Anitha's work on validation of QuikSCAT and NCEP winds, were very useful in the course of this work. We thank Y. Masumoto for the ADCP data. The QuikSCAT wind data were obtained online (ftp://podaac.jpl.nasa.gov/pub/ocean_wind/ quikscat) from the Physical Oceanography Distributed Active Archive Center (PO.DAAC), NASA Jet Propulsion Laboratory, Pasadena, California. The TOPEX/ Poseidon data were obtained from the Center for Space Research, University of Texas at Austin, Austin, Texas (information online at http://www.csr.utexas.edu/sst/ gsdata.html). The Jason-1 altimeter data were obtained from AVISO, Ramonville St. Agne, France (http:// www.aviso.oceanobs.com/html/donnees/produits/ msla_uk.html).

\section{REFERENCES}

Anderson, D. L. T., and D. J. Carrington, 1993: Modeling interannual variability in the Indian Ocean using momentum fluxes from the operational weather analysis of the United Kingdom Meteorological Office and European Centre for Medium-Range Weather Forecasts. J. Geophys. Res., 98, 12 483-12 499.

Bubnov, V. A., 1994: Climatic zonal pressure gradient in the equatorial zone of the Indian Ocean. Oceanology, 33, 414-420.

Cane, M., 1980: On the dynamics of equatorial currents, with application to the Indian Ocean. Deep-Sea Res., 27A, 525544.

Chatfield, C., 1975: The Analysis of Time Series: Theory and Practice. Chapman and Hall, 263 pp.

Chatterji, P., and B. N. Goswami, 2004: Structure, genesis and scale selection of the tropical quasi-biweekly mode. Quart. J. Roy. Meteor. Soc., 130, 1171-1194.

Chelton, D. B., and Coauthors, 2001: Observations of coupling between surface wind stress and sea surface temperature in the eastern tropical Pacific. J. Climate, 14, 1479-1498.

Eriksen, C. C., 1979: An equatorial transect of the Indian Ocean. J. Mar. Res., 37, 215-232.

Fu, L. L., E. J. Christensen, C. A. Yamarone, M. Lefebvre, Y. 
Menard, M. Dorrer, and P. Escudier, 1994: TOPEX/ POSEIDON mission overview. J. Geophys. Res., 99, 24 36924382.

, D. Stammer, R. Leben, and D. B. Chelton, 2003a: Improved spatial resolution of ocean surface topography from the T/PJason-1 altimeter mission. Eos, Trans. Amer. Geophys. Union, 84, 247-248.

Fu, X., B. Wang, T. Li, and J. McCreary, 2003b: Coupling between northward-propagating, intraseasonal oscillations and sea surface temperature in the Indian Ocean. J. Atmos. Sci., 60, 1733-1753.

Gent, P. R., K. O'Neill, and M. A. Cane, 1983: A model of the semiannual oscillation in the equatorial Indian Ocean. $J$. Phys. Oceanogr., 13, 2148-2160.

Giese, B. S., and D. E. Harrison, 1990: Aspect of the Kelvin wave response to episodic wind forcing. J. Geophys. Res., 95, 72897312.

Godfrey, J. S., G. Johnson, M. J. McPhaden, G. Reverdin, and S. E. Wiffels, 2001: The tropical ocean circulation. Ocean Circulation and Climate: Observing and Modeling the Global Ocean, G. Siedler, J. Church, and J. Gould, Eds., International Geophysical Series, Vol. 77, Academic Press, 215-246.

Goswami, B. N., 2005: South Asian monsoon. Intraseasonal Variability of the Atmosphere-Ocean Climate System, W. K. M. Lau and D. E. Waliser, Eds., Springer-Praxis, 19-61.

— , and D. Sengupta, 2003: A note on the deficiency of NCEP/ NCAR reanalysis surface winds over the equatorial Indian Ocean. J. Geophys. Res., 108, 3124, doi:10.1029/ 2002JC001497.

Grodsky, S. A., J. Carton, and R. Murtugudde, 2001: Anomalous surface currents in the tropical Indian Ocean. Geophys. Res. Lett., 28, 4207-4210.

Han, W., 2005: Origins and dynamics of the 90-day and 30-60-day variations in the equatorial Indian Ocean. J. Phys. Oceanogr., 35, 708-728.

, J. P. McCreary, J. D. L. T. Anderson, and A. J. Mariano, 1999: On the dynamics of the eastward surface jets in the equatorial Indian Ocean. J. Phys. Oceanogr., 29, 2191-2209.

- D. M. Lawrence, and P. J. Webster, 2001: Dynamical response of equatorial Indian Ocean to intraseasonal winds: Zonal flow. Geophys. Res. Lett., 28, 4215-4218.

—, P. J. Webster, R. Lukas, P. Hacker, and A. Hu, 2004: Impact of atmospheric intraseasonal variability in the Indian Ocean: Low-frequency rectification in equatorial surface current and transport. J. Phys. Oceanogr., 34, 1350-1372.

Jensen, T. G., 1993: Equatorial variability and resonance in a wind-driven Indian Ocean model. J. Geophys. Res., 98, 22 533-22 552.

Kalnay, E., and Coauthors, 1996: The NCEP/NCAR 40-Year Reanalysis Project. Bull. Amer. Meteor. Soc., 77, 437-471.

Knox, R., 1976: On a long series of measurements of Indian Ocean equatorial currents near Addu Atoll. Deep-Sea Res., 23, 211-221.

Kuroda, Y., 2002: TRITON: Present status and future plan. JAMSTEC Tech. Rep. TOCS 5, Japan Marine Science and Technology Center, Yokosuka, Japan, 77 pp.

Le Blanc, J.-L., and J.-P. Boulanger, 2001: Propagation and reflection of long equatorial waves in the Indian Ocean from TOPEX/POSEIDON data during the 1993-1998 period. Climate Dyn., 17, 547-557.

Levitus, S., 1982: Climatological Atlas of the World Ocean. NOAA Prof. Paper 13, 173 pp. and 17 microfiche.
Liu, W. T., 2002: Progress in scatterometer application. J. Oceanogr., 58, 121-136.

Loschnigg, J., and P. J. Webster, 2000: A coupled oceanatmosphere system of SST modulation for the Indian Ocean. J. Climate, 13, 3342-3360.

Luyten, J. R., and D. H. Roemmich, 1982: Equatorial currents at semiannual period in the Indian Ocean. J. Phys. Oceanogr., 12, 406-413.

Masson, S., J.-P. Boulanger, C. Menkes, P. Delecluse, and T. Yamagata, 2004: Impact of salinity on the 1997 Indian Ocean dipole event in a numerical experiment. J. Geophys. Res., 109, C02002, doi:10.1029/2003JC001807.

Masumoto, Y., H. Hase, Y. Kuroda, H. Matsuura, and K. Takeuchi, 2005: Intraseasonal variability in the upper layer currents observed in the eastern equatorial Indian Ocean. Geophys. Res. Lett., 32, L02607, doi:10.1029/2004GL021896.

McCreary, J. P., P. K. Kundu, and R. L. Molinari, 1993: A numerical investigation of dynamics, thermodynamics and mixedlayer processes in the Indian Ocean. Prog. Oceanogr., 31, 181-244.

McPhaden, M. J., 1982: Variability in the central equatorial Indian Ocean. Part I: Ocean dynamics. J. Mar. Res., 40, 157-176.

Moore, D. W., and J. P. McCreary, 1990: Excitation of intermediate frequency equatorial waves at a western ocean boundary: With application to observations from the western Indian Ocean. J. Geophys. Res., 95, 5219-5231.

Murtugudde, R., S. Signorini, J. Christian, A. Busalacchi, C. McClain, and J. Picaut, 1999: Ocean color variability of the tropical Indo-Pacific basin observed by SeaWiFS during 1997-98. J. Geophys. Res., 104, 18 351-18 366.

_ J. McCreary, and A. Busalacchi, 2000: Oceanic processes associated with anomalous events in the Indian Ocean with relevance to 1997-98. J. Geophys. Res., 105, 3295-3306.

Murty, V. S. N., and Coauthors, 2002: First results of Indian current meter moorings along the equator: Vertical current structure variability at equator, $93^{\circ} \mathrm{E}$ during FebruaryDecember 2000. Proc. Sixth Pan Ocean Remote Sensing Conf. (PORSEC 2002), Vol. 1, Bali, Indonesia, Scientific Organizing Committee of PORSEC, 25-28.

Pacanowski, R. C., 1996: MOM2 version 2.0 (beta): Documentation, user's guide and reference manual. GFDL Ocean Tech. Rep. 3.2, Geophysical Fluid Dynamics Laboratory, Princeton, NJ, 329 pp.

_, and S. G. H. Philander, 1981: Parameterization of vertical mixing in numerical models of tropical oceans. J. Phys. Oceanogr., 11, 1443-1451.

Pegion, P. J., M. A. Bourassa, D. M. Legler, and J. J. O’Brien, 2000: Objectively derived daily "winds" from satellite scatterometer data. Mon. Wea. Rev., 128, 3150-3168.

Philander, S. G. H., 1990: El Niño, La Niña and the Southern Oscillation. Academic Press, 293 pp.

- and R. C. Pacanowski, 1980: The generation of equatorial currents. J. Geophys. Res., 85, 1123-1136.

Qiu, B., M. Mao, and Y. Kashino, 1999: Intraseasonal variability in the Indo-Pacific throughflow and the regions surrounding the Indonesian seas. J. Phys. Oceanogr., 29, 1599-1618.

Reppin, J., F. Schott, J. Fischer, and D. Quadfasel, 1999: Equatorial currents and transports in the upper central Indian Ocean. J. Geophys. Res., 104, 15 495-15 514.

Reverdin, G., D. L. Cadet, and D. Gutzler, 1986: Interannual displacements of convection and surface circulation over the equatorial Indian Ocean. Quart. J. Roy. Meteor. Soc., 112, 43-67. 
Saji, N. H., and B. N. Goswami, 1996: An improved linear model of tropical surface wind variability. Quart. J. Roy. Meteor. Soc., 122, 23-53.

,-- P. N. Vinayachandran, and T. Yamagata, 1999: A dipole mode in the tropical Indian Ocean. Nature, 401, 360-363.

Schiller, A., and J. S. Godfrey, 2003: Indian Ocean intraseasonal variability in an ocean general circulation model. J. Climate, 16, 21-39.

- — - P. C. McIntosh, G. Meyers, and R. Fiedler, 2000: Interannual dynamics and thermodynamics of the Indo-Pacific Oceans. J. Phys. Oceanogr., 30, 987-1012.

Schott, F., and J. P. McCreary, 2001: The monsoon circulation of the Indian Ocean. Prog. Oceanogr., 51, 1-123.

— J. Reppin, J. Fischer, and D. Quadfasel, 1994: Currents and transports of the monsoon current south of Sri Lanka. J. Geophys. Res., 99, 25 127-25 141.

— , M. Dengler, and R. Schoenefeldt, 2002: The shallow overturning circulation of the Indian Ocean. Prog. Oceanogr., 51, $57-103$.

Senan, R., D. Sengupta, and B. N. Goswami, 2003: Intraseasonal "monsoon jets" in the equatorial Indian Ocean. Geophys. Res. Lett., 30, 1750, doi:10.1029/2003GL017583.

Sengupta, D., R. Senan, and B. N. Goswami, 2001: Origin of intraseasonal variability of circulation in the tropical central Indian Ocean. Geophys. Res. Lett., 28, 1267-1270.

- — , V. S. N. Murty, and V. Fernando, 2004: A biweekly mode in the equatorial Indian Ocean. J. Geophys. Res., 109, C10003, doi:10.1029/2004JC002329.
Shenoi, S. S. C., P. K. Saji, and A. M. Almeida, 1999: Near-surface circulation and kinetic energy in the tropical Indian Ocean derived from Lagrangian drifters. J. Mar. Res., 57, 885-907.

Vecchi, G. A., and D. E. Harrison, 2002: Monsoon breaks and subseasonal sea surface temperature variability in the Bay of Bengal. J. Climate, 15, 1485-1493.

Vinayachandran, P. N., S. R. Shetye, D. Sengupta, and S. Gadgil, 1996: Forcing mechanisms of the Bay of Bengal circulation. Curr. Sci., 71, 753-763.

Waliser, D. E., 2005: Intraseasonal variability. The Global Monsoon System: Research and Forecast, WMO Tech. Doc. 1266 , C.-P. Chang, B. Wang, and N.-G. Lau, Eds., WMO, 403-439.

- R. Murtugudde, and L. Lucas, 2004: Indo-Pacific Ocean response to atmospheric intraseasonal variability. Part II: Boreal summer and the intraseasonal oscillation. J. Geophys. Res., 109, C03030, doi:10.1029/2003JC002002.

Webster, P. J., T. Palmer, M. Yanai, V. Magana, J. Shukla, and A. Yasunari, 1998: Monsoons: Processes, predictability and the prospects for prediction. J. Geophys. Res., 103, 14 451-14 510.

_ A. M. Moore, J. P. Loschnigg, and R. R. Leben, 1999: The great Indian Ocean warming of 1997-98: Evidence of coupled oceanic-atmospheric instabilities. Nature, 401, 356-360.

Wyrtki, K., 1973: An equatorial jet in the Indian Ocean. Science, 181, 262-264.

Zheng, Y., D. E. Waliser, W. Stern, and C. Jones, 2004: The role of coupled sea surface temperatures in the simulation of the tropical intraseasonal oscillation. J. Climate, 17, 4109-4134. 